IOo cc. of solution 0.603 gram of the salt. This value falls on the curve given in the plate.

"We see then that in solubility the permanganates bear a general resemblance to the chlorplatinates in that those of most of the heavy metals are very soluble, while those of the alkali metals, and particularly of caesium dissolve in water with difficulty. The saturated solution of the latter at $0^{\circ}$ is light violet in color, and even permits one to detect the presence in it of free acid with litmus paper. At the same temperature strontium permanganate is about 2,700 times, and calcium permanganate nearly 3,000 times, as soluble."

The specific gravity of the saturated solution of potassium permanganate at $15^{\circ}$ is 1.035 ; hence, according to the writer's determination above, Ioo parts of water dissolve $5.3 \mathrm{I}$ grams at this temperature. This value confirms the accuracy of Baxter, Boylston and Hubbard's curve and shows that the widely recorded value of Mitscherlich is considerably too high.

Austin M. Patterson.

SPRINGField, Mass.,

Oct. 4 , 1906.

\title{
REVIEW.
}

\section{REVIEW OF ANALYTICAL WORK DONE ABROAD IN I905.}

BY BENTON DALES.

Received September Io, 1906 .

IN THIS review the same general classification is used as in that of last year, and the articles are reviewed with the same purpose, namely, that an experienced chemist may be able to repeat the work. The effort is made to include a reference to the more important articles published; the review could not be made complete in reasonable space except it were a mere bibliography. The writer acknowledges his indebtedness to the Chemisches Central-Blatt for abstracts and for the general classification.

\section{GENERAL ANALYSIS.}

Büeler de Florin (Chem. Ztg. 29, 569) made some improvements. upon Secchi's method of determining the transparency of liquids. The latter recommended sinking a white disk in the liquid till it was no longer visible to the observer's eye; the distance from liquid surface to disk he called the limit of visibility of the liquid. To avoid the effect of position of the sun, clouds, etc., Büeler de Florin sank into the liquid an incandescent lamp of known lighting power and worked as much as possible at night. 
To avoid the personal equation he determined the brightness photometrically. His "transparenceometer" was illustrated in the article. Gillot and Grosjean (Bull. soc. chim. belg. I9, I90) gave an application of the pycnometer method to the determination of the weight and volume of precipitates suspended in liquids. $\quad p=\left(\mathrm{D}-d^{\prime}\right) \mathrm{V} \times k, \quad k=\frac{p}{\left(\mathrm{D}-d^{\prime}\right) \mathrm{V}}, \quad v=\mathrm{V}-\frac{\mathrm{P}-p}{d}, \quad$ and $d=\frac{p}{\mathrm{~V}-\frac{\mathrm{P}-p^{\prime}}{d}}$, where $\mathrm{P}, \mathrm{D}, \mathrm{V}$ are the total weight, density and volume respectively of the precipitate and liquid, $p, d$ and $v$ the corresponding properties of the precipitate alone and $p^{\prime}, d^{\prime}$ and $v^{\prime}$ those for the clear filtrate, while $k$ is a constant for each substance. Wagner $(Z$. offentl. Chem. II, 404) determined reducing sugars with the Zeiss immersion refractometer. The sugar was reduced as usual with Fehling's solution, the cuprous oxide filtered through an Allihn tube, washed, dissolved in concentrated nitric acid and the solution evaporated to dryness. The residue was taken up with exactly $5 \mathrm{cc}$. of 2 per cent. nitric acid of refractive index 2 I.6, diluted to Io cc. with water and then determined with the refractometer. Ducommun (Schweiz. Wöchschr. Pharm. 43, 635) recommended the use of sodium sulphide instead of ammonium sulphide in analytical separations. Ebler (Z. anorg.Chem. $48,61)$ published a general separation of the metals without the use of hydrogen sulphide. It was based upon the varying properties of the metals of forming with ammonia complex cations. Windisch (Wöchschr. Brauerei, 22, 48) continued his examination of asbestos preparations on the market and found that those of Theo. Seitz in Kreuznach were markedly better than those investigated earlier. They contained less water-soluble constituents and the ignition residue of the water extract and the alkalinity were less.

Combustion and Heating Value.-Carrasco and Carrasco and Plancher (Atti accad. lincei [5], 14, II, 608, 6I3) described a new combustion method. The heating is done by electricity inside instead of outside the tube. The absorption apparatus is of the usual form. The special tube and heating apparatus were described. They may be bought of the Vereinigte Fabriken für Laboratoriumsbedarf, Berlin. Considerable work was published upon Dennstedt's simplified combustion method (see his "Anleitung zur vereinfachten Elementaranalyse für wissenschaftliche und technische Zwecke," Meissner's Verlag, Hamburg, 1903). Dennstedt himself ( $Z$. angew. Chem. I8, I I 34 and Ber. 38, 3729), also with Hassler and Klünder (Chem. Ztg. 29, 52), gave further details and described various technical applications of the method, such as the determination of oils, coals, sulphur in 
pyrite, etc. The apparatus may be bought of Emil Dittmar and Vierth, Hamburg. In the last-mentioned article it was stated that carbon disulphide could be determined by this method and, so far, not by any other. Lippmann (Loc. cit. p. 487) took exception to this statement about carbon disulphide, maintaining that this substance could be easily determined by his own combustion method (using cupric oxide-asbestos). Furthermore he claimed that his method is accurate and superior to that by means of platinum-quartz in simplicity and cheapness. Weil (Ber. 38, 282), trying Dennstedt's method on the tin chloride double salt of "Violettcarbthiol hydrochloride," found that a crystalline substance sublimed and settled over the platinum quartz, the latter then losing its capacity to glow further. Therefore it would seem that tin like arsenic has a poisonous action upon contact masses. The Heraeus electrical combustion furnace, a modification of which is used by Dennstedt, was described by W. C. Heraeus (Pharm. Ztg. 50, 218). In studying the uncommon faults of the combustion method Herman (Z.anal. Chem. 44, 686) found that too little attention is paid to the absorption of sulphuric acid and the halogens by the glass tube and contact substances. In trying Dennstedt's method on substances containing nitrogen, sulphur and the halogens he found that for nitrogen and iodine the absorption of gaseous compounds by boats loaded for the purpose could give very good results. In opposition to Calberla $(J$. pr. Chem. I04, 232) he observed that silver at bright redness will not decompose all the oxides of nitrogen, what escapes being absorbed in the soda-lime tube. Lunge and Grossmann (Z.angew. Chem. I8, 1 249) stated that the Parr calorimeter cannot be used to obtain the heat of combustion of coals giving less than 7500 calories. With coals giving more heat satisfactory results may be obtained, if each degree of corrected temperature be multiplied by 1540 and if their instructions be closely followed. The number I 540 applies only to a Parr calorimeter of such weight as to give with 2000 grams of water the normal water value 2 I 23 .

Gas.-Lilienfeld (Ann. Physik. [4], 16, 931) gave a method for the spectral qualitative analysis of gas mixtures. The tube with outside electrodes and with a capillary fused inside is shunted in parallel to the self-inductor of an electrical circuit consisting of the source of the current, the spark gap and the self-inductor. The band spectrum falls away, the strong lines appear immediately, even with small amounts, the weaker ones after a time dependent upon the conditions of the discharge. The quick disappearance of many lines from the spectrum Lilienfeld explained as a dissociation influence of the second gas which must occur as soon as both gases have a common ion. With low pressure the negative ion of all gases is apparently free electron. He was able to detect 0.7 per cent. helium plainly in nitrogen, at least 0.93 per cent. 
argon in nitrogen (probably less), 0.7 per cent. nitrogen in mercury vapor and 0.7 per cent. hydrogen in mercury, the best previous determinations giving about Io, 37, 30 and 30 per cent. respectively. Mason and Wilson (Pr. Chem. Soc. 21, 296) found that the white hot mantle could be used as a substitute for platinum asbestos in the preparation of formaldehyde from methyl alcohol and of sulphur trioxide from the dioxide and oxygen, also as a substitute for palladium asbestos in a quartz tube for the combustion of hydrogen or carbon monoxide in air. Pöpel $(J$. Gasbel. 48, 225) devised a scheme for finding the quantity of gas by determining the ammonia. The source of supply was connected with three absorption flasks containing standard sulphuric acid, then with a common gasometer and the gas passed through for a certain length of time. Suppose that before entering the scrubbers the gas contained 8 grams of ammonia per cubic meter and afterwards I gram, while the ammoniacal wash-water contained 5 grams per liter for Iooo liters, then $5000 \div 7$ or 7 I 4.3 cubic meters of gas passed through the tube in the time of the experiment. Rimini (Atti accad. lincei [5], I4, I, 386) observed that the equation of de Girard and de Saporta (Bull. soc. chim. [3], 3I, 905) for the decomposition of hydrazine sulphate by copper salts is not true; the copper salt is much more reduced to metallic copper. This copper acting on excess of the hydrazine sulphate gives further amounts of nitrogen even in the cold. Therefore their determination of glucose is not accurate. Their direct determination of sodium nitrite is not usable as was shown by the earlier work of Curtius, Angeli and Dennstedt and Göhlich. Hydrazine sulphate and copper sulphate give, according to Rimini, $\left(\mathrm{CuSO} \mathrm{S}_{4}\left(\mathrm{~N}_{2} \mathrm{H}_{5}\right)_{2} \mathrm{SO}_{4}\right)_{2}+\mathrm{H}_{2} \mathrm{O}$.

Water.-Cribb and Arnaud (The Analyst, 30, 225) published some interesting results upon the action of weakly alkaline waters on iron. Polished pieces of steel or iron plate of a certain size were put into $100 \mathrm{cc}$. of water; this was maintained at $100^{\circ}$ for twenty-four hours, then the iron content of the water was determined. The steel plate was not attacked if the alkalinity (lime, sodium hydroxide or carbonate) of the water exceeded certain limits. With minimal alkalinity the whole surface was attacked, but with rising alkalinity the attack was confined to certain places and was deeper, the total amount of iron dissolved in every case having been about the same. Although the attack on the surface was limited to $\mathbf{I} / \mathbf{I} 00$ of the original surface the falling off of iron in solution was only 5 per cent. of the maximum amount. Then the solution of iron stopped almost suddenly. The limit with sodium hydroxide and with lime was Io to $15 \mathrm{cc}$. of tenthnormal solution, for sodium carbonate 30 to $40 \mathrm{cc}$. of tenth-normal solution. As a result of special experiments the authors combatted Dunstan's hydrogen peroxide idea of rusting and also 
Moody's conception of the action of carbon dioxide in the same process. They could not explain this action of weakly alkaline solutions on iron; it is not electrolytic for no hydrogen is evolved. Eijkman (Centrbl. Bakter. Parasitenk. I, 37, 742) found that coli bacteria thrive well at $46^{\circ}$ while other bacteria do not grow further at this temperature. He took roo cc. of a spring water (less of a suspicious sample like a river water), added about oneeighth the water volume of an aqueous solution containing ro per cent. peptone, Io per cent glucose and 5 per cent. sodium chloride, then tested in the fermentation flask. The indol test is not as sharp as this one. Gautie (Ann. chim. anal. appl. 10, 254) modified the Pere method of quantitatively determining the coli bacilli in drinking-water. Instead of using roo cc. of water he used varying amounts (80-5O-20-IO-I cc.), further 2O-I 5-5-I drops of the water sample and then correspondingly stepped down the amounts of peptone and 5 per cent. phenol solution added. In most cases it suffices to work with IOO-ID-I $c c$, and one drop. The determination should be set up in duplicate or triplicate to minimize the effect of unequal distribution of the bacilli in the water. Müller $(Z . H y g .5$ I, I) substituted iron oxychloride for ferric sulphate in Ficker's method of detecting typhus bacilli in drinking-water (precipitation of the water with ferric sulphate and sodium carbonate and solution of the settled or centrifuged precipitate in a 25 per cent. solution of neutral potassium tartrate). Five cc. of "ferri oxychlorati" sufficed for three liters of water.

Soil.-Hall (J.Agr.Sc. I, 65), in studying the value of plant ash analysis, reached the conclusion that ascertaining the fertilizer needs of soils by means of plant ash analysis was not to be regarded as a practical method which could replace chenical analysis of the soils. This could only be when some suitable test plant growing everywhere is found which will react with the particular needs of every soil and whose composition at definite times is known. Mehring ( $J$. Landw. 53, 229) found that no certain conclusion could be drawn from the determination of the loss of weight on ignition of soils with regard to the three things carbon dioxide or carbonates, chemically combined water and organic matter and that the uncertainty was increased by the use of ammonium carbonate. Neubauer (Landw. Vers.-Stat. 63, I4I) gave a simple method for the determination of phosphoric acid, potassium, sodium, calcium and magnesium in hydrochloric acid soil extracts. The solution was evaporated to dryness, organic matter destroyed by ignition, the residue washed with water into a $125 \mathrm{cc}$. flask, boiled for half an hour, diluted up and potassium and sodium determined in roo $\mathrm{cc}$. of the filtrate (see Neubauer, $Z$. anal. Chem. 39, 48r ; 43, 14). The insoluble residue and filter are boiled in the same measuring flask with dilute sulphuric acid (an amount equal to $5 \mathrm{cc}$. of concentrated acid) 
for half an hour, diluted and phosphoric acid determined in roo cc. of the filtrate by the molybdate method, using the molybdate solution prepared without ammonium nitrate. For calcium and magnesium a sample was prepared and heated as before, taken up with water, 2 to 5 grams of ammonium chloride were added, the whole heated on the water-bath till the evolution of ammonia ceased, then washed into a I $25 \mathrm{cc}$. flask, ammonia added, boiled, diluted and the metals determined in $100 \mathrm{cc}$. of the filtrate as usual. Sjollema (J. Landw. 53, 67) found that the colloid substances of a soil color themselves with sutable coloring materials, whereas quartz grains and unweathered mineral fragments do not to any great extent. Methyl violet (O.I-0.2 gram in $500 \mathrm{cc}$. water) colors amorphous silica and aluminum silicate. Aqueous solutions of naphthol yellow and Congo red color only amorphous alumina. Alizarin in dilute sodium hydroxide does not color quartz and amorphous silica but does alumina and aluminum silicate. Kaolin is usually not colored. He (Loc. cit. p. 70) separated the colloids from quartz grains, etc., by rubbing repeatedly in a mortar with water without breaking up the grains, pouring off the liquid and evaporating it to dryness, then drying in a desiccator, centrifuging for two or three minutes and taking up with a mixture of bromoform and chloroform (sp. gr. 2.5). The solution was filtered after a little standing, washed with ether and dried. Most of the non-colloidal matter he claimed would be removed with one repetition of the centrifuging.

Mineral.-Gregory (Chem. News, 92, 184) gave a rapid method for the determination of fluorspar. Two grams of substance dried at $120^{\circ}$ heated to constant weight gives carbon dioxide with sufficient exactness. Another 2 grams are heated in a platinum dish with pure hydrofluoric acid, the mixture evaporated and ignited, the operation being repeated to constant weight. In the absence of silica the loss of weight on changing calcium carbonate into fluoride is about half the weight of carbon dioxide present. The difference between the weight calculated from the carbon dioxide determination and that after treatment with hydrofluoric acid gives silica, but is not quite accurate in the presence of silicates. A third mass is fumed down with concentrated sulphuric acid. From this weight the amount obtained for silica and the calcium sulphate corresponding to calcium carbonate are subtracted and the remaining increase is a measure of the calcium fluoride converted into sulphate. Lienau (Chem. $Z$ tg. 29, 584, I 280) gave a method for the investigation of bauxite. Moisture was obtained by heating for ten hours at $110^{\circ}$ in a drying-oven. The loss on ignition was determined by heating $0.5^{-I}$ gram of the dried sample to bright redness in platinum; bauxites often contain up to I per cent. of organic matter. One gram was taken up with $5-8 \mathrm{cc}$. of sulphuric acid $(\mathrm{I}: 2)$ and 
evaporated to dryness on an asbestos plate, then taken up with $20 \mathrm{cc}$. sulphuric acid ( $\mathrm{I}: 5$ ), boiled, cooled a little, filled up quickly with boiling water and allowed to settle, then filtered. With more than io per cent. silica the residue must be fused with primary potassium sulphate. To precipitate titanium dioxicle the filtrate was decomposed with $500 \mathrm{cc}$, of at least 3 per cent. aqueous sulphur dioxide, $50 \mathrm{cc}$. of ro per cent. sodium carbonate solution were added, the whole was diluted to $900 \mathrm{cc}$. with water, heated to boiling for an hour on a sand-bath and filtered. The first $200 \mathrm{cc}$. might be cloudy and were then poured back throngh the filter. Hot water containing ammonium chloride was used for washing. The filtrate was evaporated to $500 \mathrm{cc}$. Fifty or Ioo $\mathrm{cc}$. of the solution were reduced with stick zinc wrapped with aluminum wire, poured through glass wool and titrated with tenth-normal permanganate. Alumina and ferric oxide were determined together in 200 or 100 cc., according to the amount of iron.

Volumetric.-Fuld (Münch. med. Wochschr. 52, I 197) stated that common red or blue cabbage boiled in water or allowed to stand twenty-four hours in it made a new indicator, used best with white underneath. It is red in acid and green in alkaline solution. ${ }^{1}$ The blue tone in alkaline solution with too much indicator may be removed by a suitable yellow color such as saffron. Petrow (Pharm. Ztg. 50, 990) gave also a method of preparing this indicator and said it was capable of general use, but possessed practically no advantages over phenolphthalein or methyl orange. Krebitz (Seifensiederztg., 32, 588) observed that he had used Fuld's indicator for over a year. Hildebrandt (Wochschr. Brauerei, 22, 69) gave the following table concerning the usability of certain indicators.

Pellet (Bull. assoc. chim. sucr. dist. 23, 620) gave reasons for preferring litmus to phenolphthalein for sugar factory work. Rupp and Hartmann (Arch. Pharm. 243, 98) gave an oxidimetric method of determining formic acid based upon the following reaction: $2 \mathrm{HBrO}_{3}+5 \mathrm{HCOOH}=\mathrm{Br}_{2}+6 \mathrm{H}_{2} \mathrm{O}+{ }_{5} \mathrm{CO}_{2}$. An excess of potassium bromate with dilute sulphuric acid was used and the excess titrated back. Schumacher and Feder ( $Z$. Unters. Nahr-Genussm. Io, 4I5) found that in this reaction, $2 \mathrm{KIO}_{3}+$ ${ }_{5} \mathrm{SO}_{2}+{ }_{4} \mathrm{H}_{2} \mathrm{O}=\mathrm{K}_{2} \mathrm{SO}_{4}+{ }_{4} \mathrm{H}_{2} \mathrm{SO}_{4}+\mathrm{I}_{2}$, if the sulphuric acid were neutralized by say calcium carbonate, only the first precipitated iodine would be titrated and consequently sulphur dioxide could be thus determined. Schwezow (Z. anal. Chem. 44, 85) stated that iodine dissolves in benzene with an intense red color, the reaction being more delicate than the starch blue, and he recommended its use in iodometry as an indicator. Margosches (Loc. cit. p. 392)

1 The use of an infusion of red cabbage as an indicator is mentioned in "Comstock's Chemistry," published in Hartford in 1831 .-EDrTor. 


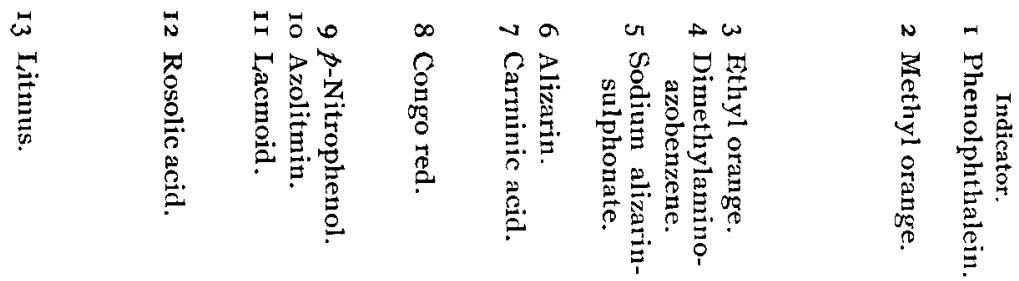

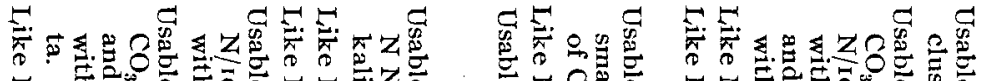

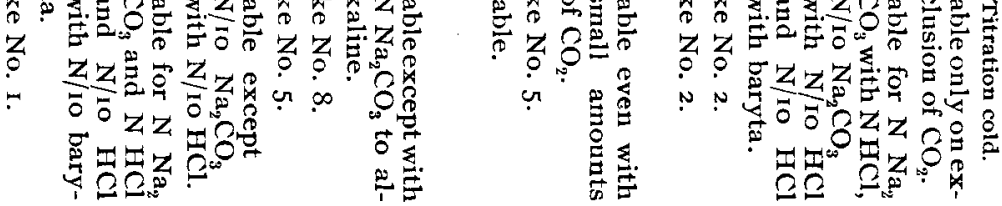

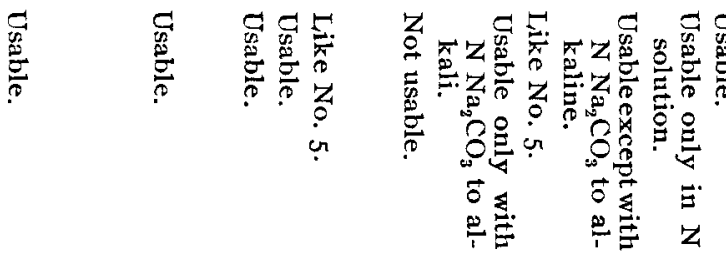

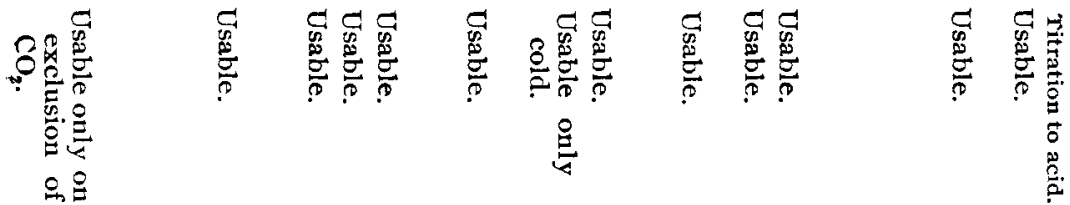

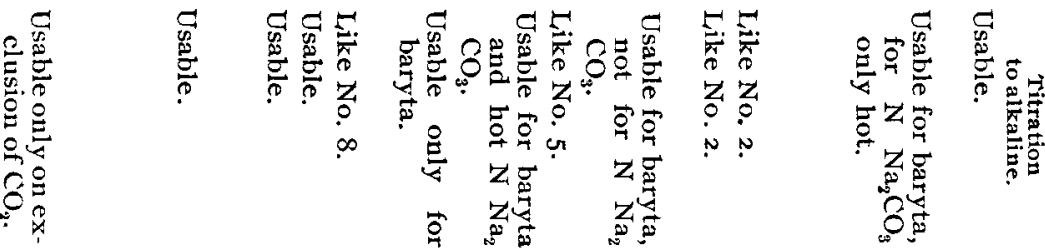

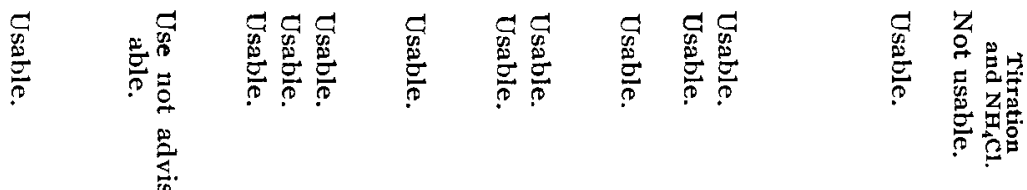

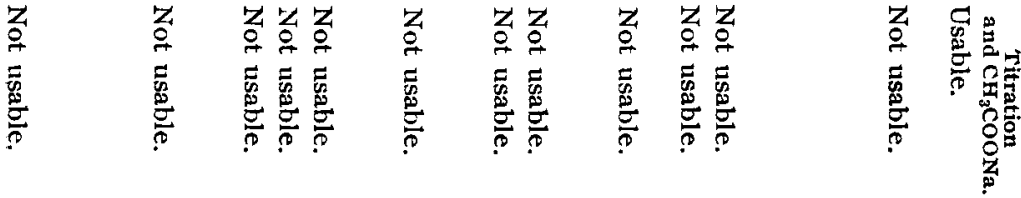


stated that this use of benzene had been given by Moride in 1852 , and that he himself with Ditz had recommended toluene in I904. Woods ( $J$. Chem. Ind. 24, I 284) gave a new indicator prepared by boiling 23 grams of the condensation product from diazo-pnitraniline and 2, 5,7-aminonaphtholdisulphonic acid with 5.5 grams of benzaldehyde, roo grams of hydrochloric acid ( $18^{\circ}$ Bé.) and 900 grams of water for fifteen minutes. It is colorless in acid, intense orange in alkaline solution. Its formula is

$$
\mathrm{C}_{10} \mathrm{H}_{14}\left(\mathrm{SO}_{3}^{5,8} \mathrm{H}\right)_{2}\left\langle\begin{array}{l}
\mathrm{N}-\mathrm{N}_{\mathrm{N}}^{2}-\mathrm{C}_{6} \mathrm{H}_{4} \mathrm{NO}_{2} \\
\mathrm{C}-\mathrm{CC}_{6} \mathrm{H}_{5}
\end{array}\right. \text {. }
$$

Sörensen and Andersen ( $Z$. anal. Chem. 44, I56), Sebelien (Chem. Ztg. 29, 638) and Lunge ( $Z$. angew. Chem. 18, 1520) discussed further the relative merits of sodium oxalate and sodium carbonate as the standard for titrations. The first-named gave their reasons for preferring the oxalate; an acid standardization by means of this substance offers absolutely no difficulty and the decomposition products of the oxalate are always the same no matter how it is decomposed so long as an alcohol flame is used as the source of heat. They observed that titration with sodium carbonate dried according to Lunge gives about the same results as those with the oxalate. The difference is never o.I per cent. and usually comes from the fact that the carbonate has given off a little more carbon dioxide than it has retained water. Sodium carbonate free from water, hydroxide and bicarbonate can, apparently, not be prepared. These authors further prefer phenolphthalein to methylorange for scientific work. Sebelien decided also in favor of sodium oxalate, saying that in the calcination of sodium carbonate some hydroxide is always formed. Its hygroscopicity is also very great, while the oxalate is fully unhygroscopic. Lunge showed that heating the oxalate with illuminating gas is as good as with alcohol, if the crucible is put into an asbestos plate with a hole of proper size to carry the crucible. He stated that the inclicator used in standardization must be the one used in the titrations. Sodium carbonate dried at $270^{\circ}$ he found to contain no hydroxide or entirely negligible traces. The carbonate is not so hygroscopic in a well-closed weighing-bottle in a desiccator; 7.9856 grams weighed after fourteen days 17.9862 grams. He stated that in moist air the oxalate also takes up water. Lunge stated further that primary sodium carbonate, recommended by North and Blakey $(J$. Chem. Ind. 24, 395) as a reliable indicator, will lose some carbon dioxide even in closed vessels.

Microscopic.-Di Cristina (Z. wiss. Mikrosk, 22, 99) gave a new method of joining together sections of material embedded in celloidin. The sections are put for a very short time in 94 per cent. alcohol, then placed upon an object glass covered with a 
layer of five parts egg albumen and one part neutral glycerol. They will then stand even treatment with absolute alcohol to remove the celloidin. Grigorjew (Vrtljschr. ger. Med. u. offentl. Sanitätswesen, 29, 79) recommended ro per cent. formalin solution for the preservation of organs and their contents for subsequent investigation. He stated it to be better than alcohol. Lamb (Collegium, 1905, 15I) and Priestman (J. Chem. Ind. 24, 23I) described the preparation of specimens and the microscopic structure of genuine sumach and its chief adulterants. Ostwald (Sitzungsber. Kgl. pr. Akad. Wiss. Berlin, 1905, 167) gave some microscopic reactions for the detection of drying oils and the nitrogenbearing cementing materials like glue, albumen and casein. Raehlmann (Vortrag vor dem Kongress zur Bekämpiung der Farbenund Malmaterialien Verfälschung $z u$ München. Protokoll 23, Weimar) observed by microscopic study of cross-sections of paintings that oil was very little used by such painters as Titian, Tintoretto and the old Dutch and German masters and that where it was used it had already gone over into varnish. Painters of the German and Dutch hey-day of the art put their colors on in distinctly separated layers. They knew how to prevent chemical decomposition and change in neighboring layers for they put in between separating indifferent layers. Pavlow (Z, wiss. Mikrosk. 22, I86) used creosote as a water-extracting material for embedding in paraffin. The objects, fixed in any solution, were put into creosotum fagi (without preliminary dehydration) for four to twenty-four hours according to their size, then two to three hours in pure creosote, the excess of this removed by filterpaper, the objects then put for an hour in xylene or toluene and finally embedded in paraffin.

\section{ANALYSIS OF INORGANIC COMPOUNDS.}

Metalloids, Oxygen.-Dickson (The Analyst, 30, 145) stated that $f$ r the determination of oxygen in copper by heating in a stream of hydrogen the copper must be subdivided as much as possible or larger pieces can be used if a metal of lower meltingpoint like tin be added to the copper. Archbutt (Loc. cit. p. 385) said that the simpler method is reliable even if the turnings are larger; the larger the pieces the slower the determination simply. Jorissen and Ringer (Chem. Weekblad, 2, 78I) compared the methods of Romijn and Bjerrum for the determination of oxygen dissolved in sea-water. Experiments with artificial solutions containing salt, calcium and magnesium chlorides showed that in the presence of II.32 per cent. magnesium the method of Romijn gave about 88 per cent. too low a value for the oxygen content of the water, while the method of Bjerrum in the presence of 0.43 per cent. calcium gave Io to 13 per cent. too low results. The presence of sodium has no effect. Legler (Pharm. Centrh. 46,272 ) determined the oxygen in water by means of sodium 
sulphite. He filled a glass-stoppered flask of 300-600 cc. with the water and added $5 \mathrm{cc}$. of sulphite solution $\left(5\right.$ grams $\mathrm{Na}_{2} \mathrm{SO}_{3}$. $7 \mathrm{H}_{2} \mathrm{O}$ in $250 \mathrm{cc}$. water) through a pipette to the bottom of the flask. He mixed the liquids, poured the contents of the flask into a measured excess of iodine solution and titrated back with thiosulphate. The pipette is used in the same way in standardizing the solutions. In one liter of water, if $5 \mathrm{cc}$. of sulphite solution and Io cc. of iodine solution are used, $O=\frac{1000}{V-s} f(n-m) \frac{O}{I 0 O}$, where $\mathrm{V}$ is the flask volume, $m$ the number of cubic contimeters of thiosulphate used in standardization, $n$ the number used in the determination, $O$ the number of milligrams of oxygen corresponding to IOO $\mathrm{cc}$. of iodine solution and $f$ a factor giving the relation of the thiosulphate and iodine solutions. Noll ( $Z$. angew. Chem, 18, 1767) gave a modification of Winkler's determination of oxygen in water. Noll's manganese solution consisted of $2 \mathrm{cc}$. of a 50 per cent. manganese chloride solution, $2 \mathrm{cc}$. of a 40 per cent. sodium hydroxide solution and $20 \mathrm{cc}$. of water shaken together in a capacious flask till brown, then $50 \mathrm{cc}$. of concentrated hydrocbloric acid were added and the solution made up to $300 \mathrm{cc}$. with distilled water. Then he added to $100 \mathrm{cc}$. of distilled water and to $100 \mathrm{cc}$. of the water sample each $10 \mathrm{cc}$. of 5 per cent. potassium iodide solution, and then $25 \mathrm{cc}$. of the manganese solution, allowed the mixture to stand five minutes and determined the iodine liberated. Rumpel (A poth. Ztg. 20, 984) found that many medicinal hydrogen peroxide solutions contain too much acid. Chemically pure 3 per cent. peroxide requires for Ioo $\mathrm{cc}$, I-I.2 cc. of tenth-normal potassium hydroxide. For medicinal purposes the peroxide should require not more than r cc. of normal caustic potash for Ioo ce. Rumpel found that four of thirty-four samples exceeded this. Schmatolla (Pharm. $Z \operatorname{tg} .50,64 \mathrm{I}$ ) would allow in hydrogen peroxide a maximum of o.or per cent. chlorine. He gave this test for the peroxide; 200 cc. of the water containing it are acidified with five to ten drops of dilute sulphuric acid, five to eight drops of a $\mathrm{I}$ per cent. solution of cobalt nitrate are added and then caustic potasin solution in drops. The solution will be colored brown through the formation of cobaltic hydroxide in presence of $0.5^{-1} \mathrm{mg}$. of peroxide in one liter.

Sulphur.-Bender $(Z$. angew. Chem. 18,293$)$ gave the modification of the Eschka sulphur determination used in the Westphalian Laboratory; the mixture of coal and soda-magnesia is heated in a short hard glass tube $18 \mathrm{~cm}$. long, $3 \mathrm{~cm}$. in diameter, with one end closed, the tube being held horizontal in a burette holder. At the end of the burning a porcelain dish is put under the tube because the latter usually breaks on cooling. Blacher and Koerber (Chem. Ztg, 29,722) determined combined sulphuric 
acid volumetrically by titrating the boiling solution, after addition of i cc. of tenth-normal soda solution and alcohol and phenolphthalein for indicator, with tenth-normal barium chloride to disa ppearance of the color. Brunck (Z.angew. Chem. 18, I 560) gave a new method of determining sulphur in coal. One gram of the finely powdered coal was mixed with 2 grams of a mixture of dehydrated sodium carbonate (one part) and cobaltic oxide (two parts), the mixture put into a roomy porcelain or platinum boat and this into a $30 \mathrm{~cm}$. combustion tube. Oxygen was passed through and the end of the boat away from the oxygen entrance heated with a small flame to glowing. The rest of the burning was regulated by the oxygen addition, the combustion being complete when the glowing ceased. On cooling, the contents of the boat were extracted with a little warm water, filtered and washed with water containing soda to prevent clouding. The alkaline filtrate was warmed with some hydrogen peroxide to oxidize possible sulphide, the solution acidified and the sulphuric acid precipitated as barium sulphate. The cobaltic oxide might hold some of the acid back, presumably as basic sulphate; in this case the residue was dried, dissolved in hydrochloric acid after ignition of the filter and precipitated with barium chloride. Jene (Chem. Ztg. 29, 362) stated that the wet method of solution in nitric acid and precipitation of the sulphuric acid for determining sulphur in burned pyrites is inaccurate, the results being sometimes I.5 per cent. lower than those obtained by the Fresenius fusion method. Gottlieb (Loc. cit. p. 688) observed that this was due to the fact that some pyrites contain in their ignition residues as much as 8.5 per cent. of barium oxide which would combine with I.8 per cent. of sulphur. Mennicke (Loc. cit. p. 495) did not agree with Jene that the wet method of oxidation is entirely unusable. He stated that it depended upon the purpose of the sulphur determination and that the wet method gives the residual usable sulphur in the residues. Krug (Stahl und Eisen, 25, 887) gave a method of avoiding the evils of the ordinary methods for the determination of sulphur in iron. He treated the iron chloride solution with moist silver oxide, all the iron being removed as hydroxide and the chlorine as silver chloride, and the sulphuric acid being left in the filtrate. The method he stated is tedious but will serve as a standard. He recommended for a rapid determination the separation of the iron chloride by Rothe's ether method. Silberberger in 1903 criticized Lunge's twenty-year-old method of determining sulphur in pyrites and proposed, instead of precipitating with barium chloride, to precipitate the sulphuric acid from solution acidified with hydrochloric acid by means of Io per cent. alcoholic strontium chloride and subsequent addition of 95 per cent. alcohol. He washed the strontium sulphate with alcohol and ignited it at a low temperature. Dennstedt and 
Hassler ( $Z$.angew. Chem. 18, 1562, 1903) pointed out that the error of some basic sulphate forming in Lunge's method and not dissolved by his, "I cc. of hydrochloric acid in Ioo cc.of hot water," might be avoided by adding the I cc. of concentrated acid to the dry residue after driving off the nitric acid, heating and then adding the roo $\mathrm{cc}$. of hot water. They stated there was nothing else wrong with the Lunge method. Then they gave the details of their simplified combustion method for determining sulphur in pyrites. Lunge, and Lunge and Stierlin (Loc.cit. pp. 449, I656 and I92 I) stated that a number of chemists had tried comparatively his method and Silberberger's and found the latter inaccurate, though sometimes good results were obtained through compensation of errors. He stated that he always added his "I cc. of hydrochloric acid in Ioo cc. of hot water" as Dennstedt and Hassler recommended and that that was what he meant. He gave as an explanation of the varying results of different chemists using his method not the formation of basic sulphate but the greater or less occlusion caused by the manner of adding the barium chloride. If the hot dilute barium chloride were added all at one pouring, more of it was occluded in the precipitate than if it were poured slowly. This was pointed out by Hintz and Weber and if their directions were followed for the precipitation, using Lunge's for the rest, the different errors in the determination were almost entirely compensated. Lunge stated also that Dennstedt and Hassler's combustion method of determining usable sulphur in pyrites is rational, but takes more time and apparatus than his own. The first of his articles is the report of the ninth sub-committee of the International Committee on Analysis of the Sixth International Congress for Applied Chemistry at Rome. H. S. Pattinson ( J. Chem. Ind. 24, 7) found that Silberberger's method will give accurate results but is more tedious and expensive than Lunge's, and gave a slight modification of the latter. J. Pattinson and Dunn (Loc. cit. p. Io) pointed out as sources of error in the sulphur determination that sulphur can come from the rubber stoppers used in the wash-bottles and also that pure barium chloride of commerce often contains sulphur. Von Knorre (Die Chem. Ind. 28, 2) stated that Lunge's method is better than Silberberger's. He found also that the use of benzidine hydrochloride proposed by Müller and Dürkes (Z.anal.Chem.42, 477 ) and especially the modification of their method given by Raschig (Z. angew. Chem. 16,8I8) is a widely usable and pretty method for the rapid volumetric determination of sulphuric acid, good enough for all technical and for most scientific purposes. This was confirmed by Huber (Chem. Ztg. 29, 1227). Matwin (Z.angew.Chem. 18, I 766) recommended that the sulphur in liquid combustibles be determined by burning the substance in the Drehschmidt apparatus for sulphur determination in gaseous 
combustibles. He would weigh the substance in a little spirit or oil lamp with a wick and then burn it from this. Pfeiffer ( $J$. Gasbel. 48, 977) determined sulphur in gas purification substances by burning I gram of the sample in a flask filled with oxygen and containing 25-50 $\mathrm{cc}$. of sodiun hydroxide. If the substance did not contain enough sulphur to burn, he poured glycerol over it and stuck a lighter in it. After absorption of the gases of combustion he added to the flask I cc. of 30 per cent. hydrogen peroxide and after mixing titrated the excess of alkali with normal acid and methyl orange. One cc. of alkali is equivalent to 1.6 per cent. sulphur.

Selenium and Tellurium.-Berg (Bull. soc. chim. [3], 33, I3IO) gave a method for the determination of tellurium which rests upon the formation of tellurium chloride and the ease with which this compound can be volatilized. The determination was carried out in a combustion tube drawn out and bent at right angles. The other end was connected with a hydrochloric acid generator. The substance was placed in a boat near the bend, the air displaced by hydrochloric acid gas and the tube then heated gently. The tellurium chloride volatilized and was collected in a little U-tube containing water. Gosio (Atti accad. lincei [5], I4, II, 188) recommended the use of selenites and especially tellurites for the detection of bacteria. Tellurites give a black and selenites a red precipitate with them.

Halogens,-Dittrich and Bollenbach (Ber. 38, 75I) gave a new method for the analysis of perchlorates. They put in a large platinum or nickel crucible first a la yer of sodium nitrite (chlorinefree), then the weighed substance carefully in the middle, then more nitrite, in all about 6 grams of the latter. When all melted, the mass was kept at as low a temperature as possible for half an hour, then it was extracted with warm water, silver nitrate and nitric acid added, the nitrous acid driven off on a water-bath and the silver chloride determined. Stepanow (J.russ.physik.-chem. Ges. 37, I 2) split off halogen bound to ring carbon atoms by means of sodium and alcohol. A little tube with the weighed substance was brought into an Erlenmeyer flask containing $20-40 \mathrm{cc}$. of 98 per cent. alcohol, the flask connected with a vertical condenser and heated on a water-bath. Small pieces of sodium were thrown into a flask through the condenser tube, about twenty-five times the theoretical amount of sodium being required. At the end of the reaction $20-40 \mathrm{cc}$. of water were added, then nitric acid to strongly acid reaction and the halogen was titrated according to Volhard. The reaction was first used by A. Baeyer (Ber. I2, 459) for this purpose. Wentzki $(Z$.angew. Chem. 18,696) gave a new method of separating the halogens in halide mixtures. He used mercurous halides to precipitate the halides in solution as for example mercurous chloride or bromide to precipitate mercurous 
iodide from a solution of potassium iodide. In a mixture of all three he determined in an aliquot portion of the solution the combined silver salts, then in a portion he precipitated iodine with mercurous bromide and determined in the filtrate silver chloride and bromide. In another he removed iodine and bromine with mercurous chloride and determined the silver chloride in the filtrate. Ehrenfeld (Chem. Ztg. 29, 440) separated hydrofluoric and sulphuric acids by precipitating both as barium salts, and treating with calcium chromate in acid solution when barium fluoride is transposed and barium sulphate is not. Merck (Pharm. Ztg. 50, 1022) gave a dry test for iodine compounds. He rubbed the compound with potassium persulphate and some soluble starch when a blue color was obtained in the presence of oxygenfree iodine compounds. $\mathrm{K}_{2} \mathrm{~S}_{2} \mathrm{O}_{8}+2 \mathrm{KI}=\mathrm{I}_{2}+2 \mathrm{~K}_{2} \mathrm{SO}_{4}$. Iodates he reduced to iodides by rubbing with zinc powder. $\mathrm{I}_{2} \mathrm{O}_{5}+6 \mathrm{Zn}=$ $\mathrm{ZnI}_{2}+5 \mathrm{ZnO}$.

Nitrogen.-Barbieri (Chem. Ztg. 29, 668) gave a volumetric method for the determination of nitrous acid based upon this reaction, $2 \mathrm{Ce}\left(\mathrm{SO}_{4}\right)_{2}+\mathrm{KNO}_{2}+\mathrm{H}_{2} \mathrm{O}=\mathrm{Ce}_{2}\left(\mathrm{SO}_{4}\right)_{3}+\mathrm{KNO}_{3}+\mathrm{H}_{2} \mathrm{SO}_{4}$. The end-point is the disappearance of the yellow color of the ceric solution. It is better, though, to add an excess of the ceric solution and titrate back with potassium iodide. The oxidizing power of the ceric solution is determined iodometrically or according to Knorre. Bensemann (Z. angew. Chem. 18, 816, 939, 1225) gave a method for the analysis of saltpeter. He dissolved 8 grams of the sample in water, diluting to rooo cc. He determined chlorine and sulphuric acid in $50 \mathrm{cc}$. portions. He evaporated Ioo cc, repeatedly to dryness with 16 grams of oxalic acid, finally igniting for fifteen minutes and dissolving in water to $250 \mathrm{cc}$. He determined the chlorine in $25 \mathrm{cc} . \mathrm{AgCl} \times 24.146=$ per cent. $\mathrm{KClO}_{4}$. He titrated $100 \mathrm{cc}$, with twice normal acid. The acid used represents nitrate and original chloride, also chloride from chlorate and perchlorate. To determine chlorate 20 grams of saltpeter were mixed according to Gilbert with pyrolusite and some sudium carbonate solution, the mixture dried, melted and ignited. The residue was dissolved in water and the chlorine determined gravimetrically. $\left(\mathrm{AgCl}-\left(\mathrm{AgCl}\right.\right.$ for $\mathrm{NaCl}$ and $\left.\mathrm{KClO}_{4}\right)$ ) $\times 2 \mathrm{I} .359=$ per cent. $\mathrm{KClO}_{3}$. Brown (Pr. Chem. Soc. 2I, 208; J. Chem. Soc. 87, I05I) determined organic nitrogen in drinkingwater by treating $200 \mathrm{cc}$. of the sample with potassium hydroxide and permanganate, evaporating to dryness and igniting. The determination was carried out in a retort of Jena glass or copper and the ammonia determined with Nessler's reagent. Busch (Ber, 38, 86I) used his newly discovered diphenylenedianilodihydrotriazole ("nitron," $\mathrm{C}_{20} \mathrm{H}_{16} \mathrm{~N}_{4}$ ) for the gravimetric determination of nitric acid. The reagent may be used also to test qualitatively for the acid, best as a ro per cent. solution in 5 per cent. 
acetic acid. To 5 or $6 \mathrm{cc}$. of the solution to be tested is added one drop of dilute sulphuric acid, then 5 or $6 \mathrm{cc}$. of the nitron solution. The formation of a precipitate can be detected with one part of acid in 60,000 parts of water at room temperature or in 80,000 of water at zero. A number of other salts of nitron are difficultly soluble; bromide $\mathrm{I}: 800$, iodide $\mathrm{I}: 20,000$, nitrite $\mathrm{I}: 4,000$, chromate I:6,000, chlorate I: 4,000, perchlorate I:50,000, sulphocyanate I: I 5,000, also the ferro- and ferricyanides and the picrate. Quantitatively an amount of substance equal to 0.1 gram of nitric acid is dissolved in 80-100 cc. of water, ten drops of dilute sulphuric acid added, the mixture heated nearly to boiling and then the nitron acetate solution added. The whole is allowed to stand for one and a half to two hours in ice water, the precipitate separated by suction in a Neubauer crucible and washed with as little ice water as possible. The weight is constant after drying at $110^{\circ}$ for three-quarters of an hour and multiplied by one-sixth (better 63/375) gives nitric acid. Nitrites must be previously destroyed with hydrazine salts. Gutbier ( $Z$. angew. Chem. 18,494 ) fully confirmed Busch's claims for nitron for the above purpose. Busch (Z. Unters. Nahr.-Genussm. 9, 464) said the nitron could be used for the determination of nitric acid in water. Flamand and Prager $(B e r .38,559)$ state that compounds which contain phenylhydrazine or which split it off are not satisfactorily determined by the Kjeldahl method because of the resistance of phenylhydrazine to reduction. They recommended this procedure. The substance (0.15 to $0.2 \mathrm{gram}$ ) is dissolved in Io cc. of alcohol in a $500 \mathrm{cc}$. Kjeldahl flask and heated with $0.5^{-1}$ gram of zinc dust and 2 to $5 \mathrm{cc}$. of hydrochloric acid (sp. gr. I.I9) to decolorization; this happens usually in a few minutes. Ten cc. of concentrated sulphuric acid and $0.5 \mathrm{gram}$ of crystallized copper sulphate are added and the mixture heated to the beginning of the evolution of white fumes. Then 6 grams of powdered potassium sulphate are added and the heating continued till the liquid is clear and bright green, ustually a quarter of an hour. The rest of the determination is as usual. Alvarez (Chem. News 91, I 55; Bull. soc. chim. [3], 33, 717; Gaz. chim. ital. 35, II, 427), Bay (Compt. rend. I40, 796), Frerichs (Arch. Pharm. 243, 80) and Hinrichs (Bull. soc. chim. [3], 33, I002) all pointed out that the diphenylamine blue color is not a characteristic test for nitric acid, but is given by other oxidizing agents. Alvarez used a sulphuric acid solution of mixtures of diphenylamine with resorcinol and with $\beta$-naphthol and described the colors accurately in distinguishing between nitrates, nitrites and chlorates. Frerichs shook the nitric acid out with ether, added some grains of diphenylamine, then carefully the sulphuric acid. A yellow color due to bromine, iodine or chromic acid he removed by shaking with some aqueous sulphur dioxide, then trying the 
diphenylamine reaction on the filtered ether. Hinrichs replaced the concentrated sulphuric by concentrated hydrochloric acid and stated that this gave with nitric acid and diphenylamine in the cold no reaction, but on warming to $50^{\circ}$ or with dilute solutions even to boiling the blue color was obtained. Nitrites and many other oxidizing agents give the blue color in the cold. Meisenheimer and Heim (Ber. 38, 3834) arranged an apparatus so that the following reaction might be carried out in a carbon dioxide atmosphere and the nitric oxide measured. $\mathrm{HNO}_{2}+\mathrm{HI}=\mathrm{NO}-$ $\mathrm{I}+\mathrm{H}_{2} \mathrm{O}$. Then, if present, they determined nitric acid after the nitrous acid by the use of ferrous chloride and hycirochloric acid. $\mathrm{HNO}_{3}+3 \mathrm{FeCl}_{2}+{ }_{3} \mathrm{HCl}=\mathrm{NO}+{ }_{3} \mathrm{FeCl}_{3}+{ }_{2} \mathrm{H}_{2} \mathrm{O}$. This nitric oxicie they measured in a second eudiometer. The method was criticized by Raschig (Loc. cit. p. 39II) who said there was little need for such methods and who pointed out that the determination might be more quickly made by titrating the iodine with thiosulphate. Meisenheimer and Hein (Loc. cit. p. 4136) replied that the method was intended for the determination of both acids when present together and that under those conditions the iodine could not be titrated with thiosulphate. Sörensen and Andersen (Compt. rend. des traz. d. Lab. d. Carlsberg 6, i93; $Z$. physiol. Chem. 44, 429) advanced as the reason why the ordinary Kjeldahl method will not do for lysine and its cerivatives the formation of ring-formed piperidine compounds caused by the concentrated sulphuric acid. Piperidine and its compounds do not give up all their nitrogen as ammonia in the ordinary Kjeldahl but do in the Gunning modification or that of Arnold and Wedemeyer. Trillat and Tourchet (Compt. rend. I40, 374; Bull. soc. chim. [3], 33, 304, 308) gave a new test for ammonia in water. $3 \mathrm{Cl}+\mathrm{NH}_{3}+3 \mathrm{NaOH}=3 \mathrm{NaCl}+\mathrm{NI}_{3}+$ ${ }_{3} \mathrm{H}_{2} \mathrm{O}$. They treated 20 to $30 \mathrm{cc}$. of the water to be tested with three drops of a ro per cent. potassium iodide solution and two drops of a saturated alkaline hypochlorite solution and compared the black color with that of standard solutions. The reaction they claimed is visible at one part in 500,000 and that the error does not exceed I: I0,000. Amines, amides, ureides, pyridine derivatives, nitrates and nitrites do not affect the reaction but saliva, the gastric juice, urine and meat juices give it. There is a small amount of iodine set free in the test, causing a slight yellow color which the authors said does not interfere with the color determination. In doubtful cases a comparative test with pure water can be made. A very slight excess of hypochlorite will destroy the color of the iodine while only weakening very slightly the color of the nitrogen iodice. The iodine may also be removed by chloroform. Cavalier and Artus (Bull. soc. chim. [3], 33,745 ) have tried to use this reaction for the determination of ammonia in drinking-water, but found that its lack of delicacy ( $2 \mathrm{mg}$. of ammonia in one liter) excluded its direct use with most 
drinking-waters. A strong concentration by evaporation is necessary and this removes its chief supposed advantage over the Nessler method. The nitrogen iodide disappears rapidly; the color paled for them in one minute and was entirely gone in two or three, so the colorimetric determination is very uncertain. Winteler (Chem. Ztg. 29, 689, I009) criticized Lunge and Rey's tables for the relation of content and density of highly concentrated nitric acid solutions and gave new tables of his own, differing as much as 2.5 per cent. in some places from theirs. Lunge, Veley and Manley, and Putzer (Loc. cit. pp. 933, 1072, I 207 and I22I) all contested the accuracy of Winteler's work.

Phosphorus.-Arnold and Werner (Loc. cit. p. I326) studied the behavior of the three phosphoric acids toward twenty-three reagents and found that the customary reactions for their detection are almost all useless. They proposed the following tests: For orthophosphate: cobalt meta- and pyrophosphates are reddish in color, soluble in excess of the phosphate but insoluble in acetic acid, while cobalt orthophosphate is blue, insoluble in excess of the phosphate and soluble in acetic acid. For metaphosphate: with cobaltamine solution the metaphosphate gives a brown precipitate soluble in excess of the metaphosphate, while orthoand pyrophosphates do not give precipitates. Alkaline bismuth solution also precipitates only the metaphosphate, white, soluble in excess of the phosphate. For pyrophosphate: they used copper or cadmium salts in acetic acid solution. The copper pyrophosphate is a blue-white precipitate soluble in excess of the pyrophosphate, while the ortho- and meta-salts are not precipitated. The cadmium salt is a white precipitate insoluble in excess of the pyrophosphate. Cadmium metaphosphate is also precipitated under proper conditions but it is soluble in excess of metaphosphate. Dinan (Mon. scient. [4], 19, 94) determined phosphorus in phosphor-bronze thus: He dissolved 3.5 grams of the bronze in $\mathrm{I}: \mathrm{I}$ nitric acid, filtered, washed the residue, boiled the filtrate in a beaker with 7 grams of oxalic acid and 7 grams of ammonium oxalate till a clear solution was obtained. The solution he electrolyzed at $65^{-70^{\circ}}$, with a current of $3.5^{-4}$ volts and $0.5^{-0.7}$ ampere per square decimeter, adding oxalic acid from time to time. In the filtrate he precipitated the phosphoric acid as phosphomolybdate, dried at $100^{\circ}$ and weighed. The phosphoric acid may be precipitated after the addition of 5 grams of citric acid as the ammonium magnesium compound. Hissink and Van der Waerden (Chem. Weekblad, 2, I79) discussed the formula of the phosphomolybdate precipitate and the effect of adding sulphuric acid to the solution before precipitation. They gave the following procedure for the determination of watersoluble phosphoric acid in superphosphates, etc. Twenty grams of the substance were shaken for thirty minutes with $900 \mathrm{cc}$. of 
water and this diluted to $1000 \mathrm{cc}$. To $5 \mathrm{cc}$. of the solution were added Io cc. of nitric acid, I 5 of ammonium nitrate, 25 with 25 mg. of sulphuric acid, the mixture was heated according to Pemberton (without the Petermann liquid) and then precipitated with $10+5 \mathrm{cc}$. of molybdate solution. The precipitate has the composition $\left(\mathrm{NH}_{4}\right)_{3} \mathrm{PO}_{4}$. I 2.65 $\mathrm{MOO}_{3}$ and is dissolved by 24.3 molecules of sodium hydroxide. Raschig (Z. angew. Chem. I8, 374, 953) determined phosphoric acid thus: He dissolved a weight of sample giving close to, but not more than, 0.15 gram of $\mathrm{P}_{2} \mathrm{O}_{5}$. This was precipitated in an Erlenmeyer flask with magnesia mixture and the precipitate gathered upon a couble horizontal suction filter $40 \mathrm{~mm}$. in diameter, using the clear filtrate to get all the precipitate upon the filter. The mother-liquor was sucked off as completely as possible and the precipitate washed twice, once with ro cc. of water, then $5 \mathrm{cc}$., sucking the precipitate as dry as possible each time. After raising the diminished pressure the filter and contents were transferred to a beaker, using not more than $20 \mathrm{cc}$ of water for washing, a drop of methyl orange added and the solution titrated, stirring or shaking, with hydrochloric acid. The color change is sharper according to Schucht if a blue glass is used for then when the liquid reaches acid reaction it appears through the glass suddenly green. Raschig claimed that his method is simpler than that of Hundeshagen to which Hlavnicka (Loc. cit. p. 655) called attention. Schenke (Landw. Vers.-Stat. 62,3) pointed out that the Association method (citrate) of determining phosphoric acid gives too low results compared with the Märcker method (molybdate), in the mean about 0.38 per cent. too low; but if the acid solution were nearly neutralized with ammonia and only $50 \mathrm{cc}$. instead of roo cc. of ammonium citrate solution used, very nearly the same result was obtained as with the molybdate method. Böttcher (Chem. Ztg. 29, I293) said that his own work as well as the earlier work of Märcker, Halencke and Mach showed that Schenke is wrong. Vignon (Compt. rend. I40, I449; Bull. soc. chim. [3], 33, 805) detected free white phosphorus in phosphorus sulphide by passing a stream of hydrogen over the sulphide. The presence of the phosphorus is shown by the phosphorescence of the hydrogen and the green flame of the gas when burned (with formation of phosphoric acid).

Arsenic and Antimony.-Cantoni and Chautems (Arch. sci. phys. nat. Genève [4], 19, 364) separated arsenic and antimony by placing the solution with concentrated hydrochloric acid and methyl alcohol in a $250 \mathrm{cc}$. distilling flask connected with a condenser whose small end dips into a solution of sodium hydroxide. Through the cork of the distilling flask there was a movable glass tube shoved and kept within a few millimeters of the liquid 
level. Dry air passed through the flask at room temperature will remove the arsenic completely from the flask. Antimony does not volatilize under these conditions. Mai and Hurt ( $Z$. Unters. Nahr.-Genussm. 9, 193) described an electrolytic determination of small amounts of arsenic. They used a U-tube with platinum foil electrodes; one end of the tube had a simple liquid trap, the other a $25 \mathrm{cc}$. dropping funnel whose end dipped under the solution and a delivery tube connected through a calcium chloride tube containing pumice saturated with alkaline lead solution to stop hydrogen sulphide with a bulbed absorption apparatus. The electrolyte was i2 per cent. sulphuric acid and the absorption tube contained Io cc. of hundredth-normal silver nitrate solution. The purity of the reagents having been tested by running the current and letting the hydrogen bubble through the silver nitrate for an hour, the suspected arsenic solution (not over Io cc.) was run in slowly from the dropping funnel without interrupting the current, then washed in with a little water. With arsenic the silver nitrate blackens and in two to three hours the reduction is complete. The contents of the absorption tube were washed through an asbestos filter, rinsed with 3 or $4 \mathrm{cc}$. of water, then titrated with hundreath-normal sulphocyanate. One cc. $\mathrm{AgNO}_{3}=0.1655 \mathrm{mg}$. $\mathrm{As}_{2} \mathrm{O}_{3}=0.19 \mathrm{I} 6 \mathrm{mg}$. $\mathrm{As}_{2} \mathrm{O}_{5}$. The lower limit of the determination is about $\mathrm{I} / 5 \mathrm{O} \mathrm{mg}$. For qualitative purposes the silver nitrate in the first bulb of the absorption tube will blacken with amounts down to $0.0005 \mathrm{mg}$. The bulbs can also be replaced by the ordinary dry tube for the Marsh test mirror. The authors used a current of six to eight volts and two to three amperes. The apparatus may be bought of Wagner and Munz in Munich. Similar experiments have been tried by Bloxam and by Trotman. Frerichs and Rodenberg (Arch. Pharm. 243, 348) gave a slight modification of part of the Mai and Hurt apparatus; they prefer the cell of Trotman (J. Chem. Ind. 23, I77). Mai (Z. Unters. Nahr.-Genussm. Io, 290 ), instead of totally destroying organic matter before testing for arsenic, obtained a coal-like mass by treating the dried substance with its weight of fuming nitric acid containing 5 per cent. of sulphuric acid and gradually driving this off. The residue he distilled with five or six times its weight of hydrochloric acid (sp. gr. I.Ig) and distilled off one-fourth to one-third the liquid; all the arsenic goes over as the trichloride. The distillate he treated with one-fourth its volume of nitric acid, evaporated almost to dryness, then added cautiously sulphuric acid and heated to the appearance of white fumes. This he diluted and electrolyzed in the Mai and Hurt apparatus. Vitali (Boll. chim. farm. 44, 49) observed that the yellow compound formed by the action of arsine on mercuric chloride $\left(\mathrm{AsHg}_{2} \mathrm{Cl}_{2} .5 \mathrm{H}_{2} \mathrm{O}\right)$ can be used as a test for mercury, 0.001 to 0.0001 gram of mercuric 
chloride with zinc, hydrochloric acid and arsenious oxide giving the color. It was noted in 1890 by Franceschi that in testing for arsenic one had to look out for mercury compounds, especially mercuric chloride. Vitali found that stibine and phosphine give similarly colored compounds. Vortmann and Metzl ( $Z$. anal. Chem.44,525) precipitated antimony quantitatively as the trisulphide by heating to boiling the solution containing for each IOO $\mathrm{cc} .24 \mathrm{cc}$. of concentrated hydrochloric acid, placing the containing vessel in a boiling water-bath and passing in a rapid current of hydrogen sulphide. The precipitate was at first yellowish, then redder and finally quickly black; the precipitation was accomplished in thirty to thirty-five minutes. The solution was then diluted with the same volume of water and the treatment with hydrogen sulphide repeated. The precipitate was filtered through a Gooch crucible, washed with water, then alcohol and heated in a current of carbon dioxide to $270-280^{\circ}$. Or it is simply dried for twenty to thirty minutes at $\mathrm{I} \mathrm{IO}^{\circ}$, allowed to cool and weighed. The precipitate might be filtered on to a paper filter and ignited in a weighed crucible containing a weighed amount of a mixture of three parts of ferric oxide and one part of ferric nitrate. On ignition the trisulphide would be converted into the pentoxide. Knowing the amount of ferric oxide coming from ignition of the weighed amount of the iron mixture by previous experiment the excess in weight gives the weight of the antimony pentoxide. Antimony they separated from tin by dissolving the sulphides of both metals in $I:$ I hydrochloric acid, neutralizing with sodium carbonate or hydroxide, using phenolphthalein, diluting to a definite mark ( $50-60 \mathrm{cc}$.), adding the same volume of concentrated phosphoric acid (sp. gr. I.3) and for every roo cc. $20 \mathrm{cc}$. of concentrated hydrochloric acid, then treating with hydrogen sulphide as above. Antimony trisulphide was precipitated.

Carbon, Boron and Silicon.-Goutal (J.Gasbel. 48, I006) gave an equation for determining the heating value of a coal. $82 \mathrm{C}+$ $a \mathrm{~V}=$ heating value, where $\mathrm{C}$ stands for the fixed carbon in the coal, $V$ the volatile constituents and $a$ a variable factor dependent upon the volatile constituents $V_{1}$ of the pure (water- and ash-free) combustible. He gave values of $a$ for all heating substances which in the pure state contain less than 40 per cent. of volatile constituents. Castellana (Atti accad. lincei [5], I4, I, 465) tested for borates and for boric acid by heating the substance with an excess of potassium ethylsulphate till the first vapors come out of the little tube; these burn with a distinct green colored edge to the flame. Testing organic substances like milk he used the calcined residue from 5 to io grams. The limit of sensitiveness is $0.5 \mathrm{mg}$. of boric acid. By careful heating of formic, acetic, butyric, valeric, pelargonic, oxalic, benzoic, salicylic, cinnamic acids and also $\beta$-naphthol with potassium 
ethyl sulphate the characteristic odors of their esters were obtained. Von Spindler (Chem. Ztg. 29, 582) determined boric acid by acidifying the ash of an organic substance with hydrochloric acid, washing into a flask, making alkaline with sodiun hydroxide then adding helianthin and lastly phosphoric acid dropwise till the indicator turned red. The flask had a two-holed rubber stopper through one hole of which was inserted a distillation tube and sidewise bent tube (as in the Kjeldahl) leading to a condenser and through the other a little dropping funnel for the methyl alcohol. The aqueous liquid was distilled off as far as possible, best to dryness, then methyl alcohol was added in Io cc. amounts, distilling each amount separately till a drop taken from the condenser on a glass rod burned no more with a green flame. Distillation was then carried out once or twice more with rocc. amounts of the methyl alcohol. The whole distillate was then treated with a large excess of normal sodium hydroxide, the alcohol boiled off and the liquid evaporated to 20 or $30 \mathrm{cc}$. After cooling, an equal volume of neutral glycerol was added and the excess of hydroxide titrated back with normal sulphuric acid. Phillips ( $Z$. angew. Chem. I8, I969) determined silicon and silica together by dissolving the pulverized mixture in hot caustic potash, whereby for one atom of silicon two molecules of hydrogen are liberated, from which it is easy to calculate the silicon. The sum of silicon and silica was obtained by fusing another sample with sodium carbonate and potassium nitrate and the usual silica determination.

Metals, Alkalies.-Alvarez (Chem.News, 9I, I46;Compt.rend. I40, I 86 ; Gaz. chim. ital. 35, II, 463) recommended a 5 per cent. solution of sodium amino- $\beta$-naphtholsulphonate, I, 2, 6- $\left(\mathrm{C}_{10} \mathrm{H}_{5}\left(\mathrm{NH}_{2}\right)\right.$ $(\mathrm{OH})_{2}\left(\mathrm{SO}_{3} \mathrm{Na}\right)_{8}$, eikonogen) as a test for potassium. The reaction is as delicate as that with chlorplatinic acid. In neutral solutions with potassium salts the corresponding potassium salt of the acid is obtained as brilliant orthorhombic plates, little soluble in water, insoluble in absolute alcohol. The reaction does not take place very rapidly; in 5 to ro per cent. potassium chloride solution the precipitate forms immediately, in 3 to 5 per cent. solution after ten minutes, in 2 per cent. after a while and in I per cent. after a few hours. Klinkerfues (Chem. Ztg. 29, 77, 1085) gave an easy potash determination. He precipitated potassium chlorplatinate, washed it by decantation through a filter with alcohol, dissolved the precipitate in hot water and filtered through the same filter into a weighed platinum dish. The filtrate was treated with a couple of drops of formic acid and evaporated partially to dryness. The platinum was reduced and stuck tightly to the dish. He removed the solution and washed the residue with water or 5 per cent. nitric acid. The dish was then gently ignited and weighed after cooling in a vacuum desiccator. 
Novotny (Z. Elektrochem., 2, 453) determined volumetrically sodium hydroxide in the presence of the carbonate by obtaining first in one portion the total alkalinity with a strong mineral acid and methyl orange, then in another the free alkali after adding barium chloride with oxalic acid and phenolphthalein. The solubility of the barium carbonate might be driven back by a large excess of barium chloride and then even hydrochloric acid could be used for the titration. Reichard (Chem.Z̈tg. 29, 861) found that hydrofluosilicic acid will precipitate sodium and potassium from most concentrated solutions of salts of the two metals and lithium, leaving the latter in solution. The precipitated sodium and potassium may be determined as usual by conversion into sulphates and determining also the sulphuric acid. With lithium present the precipitation of barium sulphate is valueless because of occlusion. Potassium chlorplatinate he found also to carry down lithitum. Grossmann (Loc. cit. p. 137) and Rupp (Loc. cit. p. 443) preferred the gas volumetric method for the analysis of commercial sodium peroxide to any of the titration methods which all give too low results. Rupp regarded the fact that his titration method does give too low results as proof that the technical product contains higher oxides. Rupp and Rössler (Arch. Pharm. 243, 104) determined ammonium salts by titration with alkali hypobromite (Io grams of $\mathrm{NaOH}$ in 500 cc. of water $+\mathrm{I} 7$ grams of $\mathrm{Br}$ ). A suitable volume of the ammonium salt solution was placed in a glass-stoppered vessel and shaken with a known volume of the bromine liquor diluted with water to $50-75 \mathrm{cc}$. The iodine value of the bromine liquor should be accurately known. After five to ten minutes the liquid was diluted again with $50 \mathrm{cc}$. of water, acidified with dilute hydrochloric acid and potassium iodide immediately added. The iodine was titrated after about two minutes. There should be half or one-third the original amount of bromine liquor in excess. Free ammonia solutions must be much diluted for the determination. The oxidation was complete when the sample titrated with starch paste did not blue again on standing for a few minutes. One cc. of tenth-normal iodine $=0.0022037$ gram of ammonium sulphate, 0.00267 gram of ammonium nitrate, 0.001784 gram of ammonium chloride or 0.0005667 gram of ammonia.

Alkaline Earths.-Blum (Z. anal. Chem. 44, 9) observed that a portion of any ammonium sulphide precipitate which does not dissolve in hydrochloric acid should always be tested for barium and strontium sulphates, if it is a question of finding small amounts of these elements. Knett (Sitzber. Akad. Wiss. Wien, I13, 753; N. Jahrb. Mineral. 1905, p. 343) reported that the Karlsbad hot springs, though they show no barium on chemical analysis, do in the course of time deposit a very small amount of crystals of barium sulphate which are radioactive. Knett said they 
evidently contain radium sulphate and constitute the first uraniumand thorium-free source of radioactive material. De Koninck (Bull. soc. chim. Belg., I9, 86) found that the limit of sensitiveness of the ammonium sulphate precipitation for strontium is I : 20,000 and that strontium and calcium cannot be separated by precipitating strontium with ammonium sulphate and washing with a solution of this salt. He stated further that the solubility of strontium sulphite in the presence of sodium sulphite is about the same as that of strontium sulphate in the presence of ammonium sulphate. Koppeschaar $(Z$.anal. Chem.44, 184) gave a new method of determining magnesium carbonate in limestones. $\mathrm{He}$ treated 50 grams of the stone with $500 \mathrm{cc}$. of pure hydrochloric acid ( 150 cc. of 25 per cent. $\mathrm{HCl}$ diluted to $500 \mathrm{cc}$.), then he added to the solution $50 \mathrm{cc}$. of concentrated sulphuric acid, cooled and filtered through a porcelain funnel, washing the gypsum left in the beaker on to the filter with the filtrate. The amount of calcium sulphate he obtained by weighing the tared funnel. The filtrate he made ammoniacal, precipitated the calcium still in the solution with 5 grams of ammonium oxalate and precipitated the magnesium in the filtrate with 4 grams of sodium phosphate. $\mathrm{Mg}_{2} \mathrm{P}_{2} \mathrm{O}_{7}$ $\times \mathrm{I} .8=$ per cent. $\mathrm{MgCO}_{3}$, in the limestone.

Iron, Aluminum, Chromium and Rare Earths.-The brown color (ferrous salt, nitric and sulphuric acids) may be used as a test for ferrous salt in the presence of ferric according to Blum ( $Z$. anal. Chem. 44, Io), by strongly acidifying with sulphuric acid, then adding a crystal of potassium nitrate, when reddish streaks starting from the nitrate will soon show. Divine ( $I$. Chem. Ind. 24, 2) observed that if about o.ro gram of alumina in solution be treated with $2 \mathrm{cc}$. of a 25 per cent. solution of tannin then ammonia be added in slight excess, and the solution boiled till the excess is almost gone, the alumina will be precipitated in an easily washed and filtered form. Funk (Z.angew.Chem. 18, I687) found that on double precipitation with great excess of ammonia and washing with hot 5 per cent. solution of ammonium chloride it was possible to separate iron from zinc. The amount of ammonia should be twenty to thirty times that required for precipitation. He said also that the acetate method is a better one. Giles (Chem. Neres, 92, I, 30) found that when a nitric acid solution of the rare earths was treated with lead carbonate in excess thorium, zirconium, trivalent cerium and ferric iron were completely precipitated, tetravalent uranium, trivalent chromium and alumina slowly and incompletely, and ceric cerium and the oxides of lanthanum, neodymium, praseodymium, samarium and the yttrium group not at all. The lead was removed by hydrogen sulphide from the nitric acid solution of the precipitate. Kleine (Stahl und Eisen, 25, I305) determined chromium and manganese both by titration. Five grams of the steel were dissolved by warming in 
$50 \mathrm{cc}$. of hydrochloric acid (sp. gr. I.I2), heated to boiling, $3 \mathrm{cc}$. of nitric acid (sp. gr. I.4) added dropwise and the solution evaporated to syrupy thickness. The iron was removed from the cooled solution by means of Rothe's ether-shaking apparatus, then the solution was evaporated to ciryness. Ten cc. of sulphuric acid ( I : Io) were added, the whole washed into a flask with hot water, boiled for fifteen or twenty minutes after the addition of $\mathrm{I} 5 \mathrm{O} \mathrm{cc}$. of ammonium persulphate (6o grams per liter), filtered through an asbestos filter and the precipitate washed with cold water. An excess of ferrous sulphate solution was added to the filtrate and the excess titrated back with permanganate. The same volume of ferrous sulphate solution was titrated with permanganate and the difference gave the amount of iron oxidized by the chromic acid present. The chromium titer of the permanganate is equal to the iron titer multiplied by $0.3 \mathrm{I}$. The precipitate of hydrated manganese dioxide with the asbestos filter was treated with Io cc. of sulphuric acid $(\mathrm{I}: 3)$ and $\mathrm{I} O \mathrm{cc}$. of oxalic acio $(47.5 \mathrm{grams}$ of the acid in two liters of water mixed with $3200 \mathrm{cc}$. of water and $800 \mathrm{cc}$. of sulphuric acid), diluted to $200-300 \mathrm{cc}$. with hot water, shaken up, treated with more oxalic acid, if necessary, and titrated with permanganate. A similar amount of oxalic acid solution was titrated with permanganate and the difference gave the manganese. The manganese titer is equal to the iron titer multiplied by 0.501 . Kolb and Ahrle ( $Z$. angew. Chem. 18, 92) found that cinnamic, benzoic, salicylic and especially $m$-nitrobenzoic acid are suited to the separation of thorium from the cerium group earths. Neutral aqueous solutions of a thorium salt give with the latter acid a white flocculent precipitate. If the influence of the free mineral acid be set aside by the addition of aniline $m$-nitrobenzoate the precipitation is complete. Cerous, lanthanum and didymium salts are not precipitated either in hot or cold solution. Ceric salts are precipitated, hence nust be redtuced by hydrogen sulphide. De Koninck (Bull. soc. chim. Belg., I9, I8r) observed that ferrous and ferric salts give with alkali sulphides a black precipitate of ferrous sulphide while the supernatant liquid has a green or in very dilute solutions a brown tint. The reaction takes place with $0.25 \mathrm{mg}$. of iron per liter or one part in 4,000,000; it is comparable to the ferrocyanide reaction in delicacy. The change from brown to green is not due to oxidation or reduction nor to formation of double sulphides but probably to a molecular change like that of manganese sulphide (reddish to green), cadmium sulphide (yellow to red), mercury and antimony sulphides (reddish to black). Marre (Rev. gén. chim. pure et appl. 8, I53) recommended the volumetric iron determination proposed in I9O4 by Tarugi and Silvatici (ferric solution reddened by potassium sulphocyanate and decolorized by potassium oxalate). 
Manganese, Zinc, Cobalt and Nickel.-Blum (Z.anal.Chem.44,7) observed that barium must be removed with sulphuric acid from manganese ores containing it or else the manganese determination as the sulphide will come out too high because of barium sulphate precipitated by oxidation products of the sulphur of the yellow ammonium sulphide. Gröger (Chem. Ztg. 29, 987) determined manganese in the presence of chromium by a modification of the Volhard method for its determination in the presence of iron. He used an emulsion of zinc sulphate, basic zinc sulphate in zinc sulphate solution ( 288 grams of pure crystallized zinc sulphate in solution mixed with 28 grams of caustic potash, in 500 cc. of water, kept in a closed flask and shaken before using). He added this to the manganese chromium mixture in a $250 \mathrm{cc}$. flask on a boiling water-bath till the precipitate was no longer green but gray-violet, cooled, filled to the mark, shook up and filtered. Fifty cc. of the filtrate were boiled with a solution of 20 grams of pure crystallized zinc sulphate in $\mathrm{r}_{5} \mathrm{O} \mathrm{cc}$. of water and titrated with tenth-normal permanganate to redness. In the presence of larger amounts of chromium than o. I gram he used a larger flask than $250 \mathrm{cc}$. Nissenson and Kettembeil (Chem. Ztg. 29, 95 I), in work done at the instance of the International Committee, compared the methods of zinc determination and decided that the electrolytic, Schaffner's sodium sulphide and the ferrocyanide methods give equally good results. Hattensaur (Loc. cit. p. I037) criticized Nissenson and Kettembeil for overlooking Schneider's method. Pozzi-Escot (Ann. chim. anal. appl. 10, I47) added to a very dilute cobalt solution a few drops of an alcoholic solution of phenyl- or phenylnaphthylthiohydrantoic acid and a drop of ammonia. An immediate crimson color appeared. In more concentrated solutions a reddish brown precipitate was obtained. Nickel gave an ochre-yellow color or a dirty gray precipitate which concealed the cobalt reaction, but the nickel compound dissolved in excess of ammonia while the cobalt came out more sharply. Rubricius (Stahl und Eisen, 25, 890) described a persulphate method of determining manganese in iron and steel. The steel turnings ( 0.25 gram) were dissolved in nitric acid ( $\mathrm{sp}$. gr. I.2) and concentrated over the open fire to about half the volume of the solution, treated with Io cc. of tenth-normal silver nitrate solution, diluted to about $300 \mathrm{cc}$, boiled and treated with Io $\mathrm{cc}$. of a Io per cent. solution of ammonium persulphate. The well-cooled solution containing all manganese as permanganate was titrated with a solution of 3 grams of arsenious acid and 9 grams of alkali bicarbonate in six liters of water to the green color. Kunze (Chem. Ztg. 29, IoI7) described a method similar to this one of Rubricius. Skrabal ( $Z$. Elektrochem. I I, 653) stated that there is an intermediate labile product, the manganic salts, in the oxidation of oxalic acid by permanganate and that the 
manganous salt added acts as an inductor, forming manganic salts with the permanganate and the oxalic acid reduces this. Tschugaew (Ber. 38, 2520) gave a test for nickel. The liquid to be tested was made strongly alkaline and shaken several times to convert cobalt salts into complex cobaltic compounds, then powdered $\alpha$-aimethylglyoxime $\left(\mathrm{CH}_{3} . \mathrm{C}(: \mathrm{N} . \mathrm{OH}), \mathrm{C}(\mathrm{N} . \mathrm{OH}), \mathrm{CH}_{3}\right)$ was added and heated to boiling. If the nickel solution was not too dilute, a scarlet precipitate was obtained, with smaller amounts a red scum and with traces the yellow solution deposited a reddish precipitate, recrystallizable from chloroform and alcohol. The compound is $\mathrm{CH}_{3} \cdot \mathrm{C}--\mathrm{C} \cdot \mathrm{CH}_{3} \cdot \mathrm{C}_{4} \mathrm{H}_{3} \mathrm{O}_{2} \mathrm{~N}_{2}$. The reaction

\section{N.O.Ni.O.N}

shows plainly O.I $\mathrm{mg}$. of nickel in the presence of $500 \mathrm{mg}$. of cobalt. The delicacy for pure or cobalt-free nickel solutions is greater than $I: 400,000$.

Silver, Lead and Mercury.-Dittrich and Reise (Ber. 38, 1829) gave a determination of lead, using persulphate in acid solution. They added to lead nitrate solution a to per cent. solution of ammonium persulphate and obtained white crystalline lead sulphate, which on standing or warming in the persulphate liquid changed incompletely into lead dioxide. The precipitation was ended in five hours, the precipitate being filtered and washed with a solution of ammonium sulphate. After being burned the residue changed quantitatively into lead sulphate on the addition of a few drops of sulphuric acid. Ebler $(Z$. anorg. Chem. 47, 377) gave a gasometric and titrimetric method of determining mercury with hydrazine salts. ${ }_{2} \mathrm{HgCl}_{2}+\mathrm{N}_{2} \mathrm{H}_{4}={ }_{4} \mathrm{HCl}+{ }_{2} \mathrm{Hg}+\mathrm{N}_{2}$. This $\mathrm{re}-$ action takes place in the presence of sodium acetate. The nitrogen may be measured in a Schiff nitrometer. The method may be used for hydrazine as well. In ammoniacal solution the separation of nitrogen by hydrazine is also quantitative, mercury being reduced to the metal. Instead of measuring the nitrogen the excess of hydrazine can be titrated with iodine solution in the presence of primary potassium carbonate. Silver and copper must be previously removed. $\mathrm{L}$. and $\mathrm{J}$. Gadais (Ann. chim. anal. appl. 10, 98) detected lead in tartar as follows: The hydrochloric acid solution, to which was added 0.15 gram of copper as the nitrate was precipitated with hydrogen sulphide, filtered after standing twelve to twenty-four hours, dissolved in nitric acid, filtered and electrolyzed in platinum. Lead will give on the addition of three to four drops of tetramethyldiaminodiphenylmethane an intense blue color, by which o.I $\mathrm{mg}$. of lead as the dioxide may be recognized. Lidholm (Ber. 38, 566) separated silver and lead by dissolving the alloy or mineral, finally adding tartaric acid, filtering, neutralizing the filtrate, treating with sodium acetate (dissolving the precipitated basic lead acetate in 
acetic acid), boiling and treating with $2 \mathrm{cc}$. of a 4 per cent. solution of hydroquinol for each o.I gram of silver. Silver is precipitated and is washed as usual with 5 per cent. ammonium nitrate. Rupp (Arch. Pharm. 243, 300) gave a titrimetric method for determining mercury. He made a few cubic centimeters of a 35 per cent. solution of formaldehyde alkaline, decomposed it with a suitable volume of the mercury solution, warmed for ten or fifteen minutes on the water-bath, allowed to cool and acidified with much acetic acid. He then added tenth-normal iodine solution in excess, shook gently for five minutes, keeping well closed, then titrated the iodine excess with thiosulphate in the presence of starch. One cc. of iodine solution $=0.01002$ gram of mercury or 0.01355 gram of mercuric chloride. Utz (Pharm. Post, 38, 49I) said Rupp's method could be used for the determination of sublimate in dressings.

Copper, Cadmium and Bismuth.-Ebert (Apoth. Ztg. 20, 908) gave a test for very small amounts of copper. A mineral water showing no copper with hydrogen sulphide, potassium ferrocyanide, etc., colored some wadding through which it was filtered pale green. If water made slightly alkaline (one or two drops for $500 \mathrm{cc}$.) be filtered three times through a funnel provided with a bunch of wadding and the latter remains colorless, there is no copper in the water. Ebler $(Z$, anorg. Chem. 47, 37 I) determined copper with hydrazine salts. ${ }_{4} \mathrm{Cu}\left(\mathrm{NH}_{3}\right)_{4} \mathrm{SO}_{4}+\left(\mathrm{NH}_{2}\right)_{2} \mathrm{H}_{2} \mathrm{SO}_{4}=$ ${ }_{2} \mathrm{Cu}_{2}\left(\mathrm{NH}_{3}\right)_{4} \mathrm{SO}_{4}+\mathrm{N}_{2}+2 \mathrm{NH}_{3}+3\left(\mathrm{NH}_{4}\right)_{2} \mathrm{SO}_{4}$. The blue cupric salt goes over into colorless cuprous salt and all the nitrogen of the hydrazine is set free (see Rimini, under "Gas Analysis"). He used a Hempel nitrometer, but drove the gas over by slow distillation and collected over mercury. De Koninck (Bull. soc. chim. Belg., I9, 9I) recommended Cloud's colorimetric determination of bismuth (varying color of lead iodide containing bismuth), stating that amounts of bismuth as low as $0.02-0.03 \mathrm{mg}$. per IOO cc. of solution could be detected with certainty. Meerburg and Filippo (Chem. Weekblad, 2, 64I) stated that $0.000 \mathrm{I} \mathrm{mg}$. of copper might be detected by adding to the hydrochloric acid solution of the copper salt cesium chloride. With little of the latter, red crystals of perhaps $\mathrm{CuCl}_{2} \cdot \mathrm{CsCl}$ are formed. With more cesium chloride yellow crystals of perhaps $\mathrm{CuCl}_{2} \cdot 2 \mathrm{CsCl}$ are formed, which turn red on the addition of small amounts of cupric chloride. Cobalt and iron interfere but lead and bismuth do not. Salkowski (Ber. 38, 3943) commended, and Staehler and Scharfenberg (Loc. cit. p. 3862) gave some details of the quantitative determination of bismuth as the phosphate and its separation from the other heavy metals, especially copper, cadmium, mercury and silver. Bismuth phosphate is insoluble in dilute nitric acid. Ten to $20 \mathrm{cc}$. of a solution of bismuth in concentrated nitric acid are diluted with $300-400 \mathrm{cc}$. of water. To the boiling 
solution is added dropwise the necessary amount of boiling io per cent. sodium phosphate (tertiary) with stirring. If the solution should become alkaline, it is acidified with a little nitric acid. The whole is boiled for a while, allowed to settle, filtered hot and the precipitate washed with hot I per cent. nitric acid containing a trace of ammonium nitrate. The precipitate is then dried at $120^{\circ}$, ignited for fifteen or twenty minutes over a large Bunsen burner and weighed as $\mathrm{BiPO}_{4}$. The other metals named are left in the filtrate.

Molybdenum, Vanadium, Tin, Etc.-Blum (Z. anal. Chem. 44, 2) gave a test for stannous tin depending on his test for ferrous iron. If a stannous solution containing hydrochloric acid be treated with a few drops of ferric chloride solution, ferrous chloride corresponding in amount to the stannous compound is obtained. The ferrous chloride can then be detected by treatment with sulphuric acid and the potassium nitrate crystal. The hydrochloric acid should be driven off by heat before the nitrate crystal is added. Glasmann (Ber. 38, I93) gave an iodometric method of determining the alkali heptamolybdates. An aqueous solution of ammonium heptamolybdate liberates iodine from the potassium iodide-potassium iodate mixture, because the salt hydrolyzes to free molybdic acid and neutral molybdate and the free acid acts in the known way with the mixed iodine compounds. He further (Loc. cit. p. 6oo) gave an oxidimetric method for the determination of molybdic and vanadic acids together. Vanadic acid is reduced in sulphuric acid solution by zinc to $\mathrm{V}_{2} \mathrm{O}_{2}$, by magnesium to $\mathrm{V}_{2} \mathrm{O}_{3}$. Molybdic acid gives with each metal in the presence of air $\mathrm{MO}_{2} \mathrm{O}_{3}$. If then aliquot portions of the solution be recuced with zinc and acid and magnesium and acid and both recuced solutions be titrated with permanganate (and manganese sulphate) enough data may be obtained so that both acids can be calculated. Von Knorre (Loc. cit. p. 783) determined tungsten in the following manner: He added to the cold tungstic acid solution some dilute sulphuric acid or alkali sulphate and then precipitated with a solution of benzidine hydrochloride. The crystalline benzidine sulphate surrounds the benzidine tungstate so well that though the latter filters poorly by itself it can be easily filtered after five minutes and ignited in platinum while still moist to $\mathrm{WO}_{3}$. Melikow and Jeltschaninow (J. russ, physik.-chem. Ges. 37 , 99) observed that potassium fluorpercolumbate is colored yellow by hydrogen peroxide in small amounts in the presence of sulphuric acid and that concentrated solutions of potassium percolumbate are colored yellow by concentrated sulphuric acid. One-tenth per cent. of columbium in tantalum preparations can be detected by the help of these reactions. Puschin and Trechcinsky (Loc. cit. p. 828) se parated tin from cobalt and nickel by making use of the fact that tin will come out of an acid solution 
of tin ammonium oxalate on electrolysis while cobalt and nickel come out of neutral solution. Nickel or cobalt oxalate precipitates in the liquid, but the electrolysis of the tin salt is carried out and then the nickel or cobalt salt is dissolved by the addition of ammonia and warming. Antimony in nitric acid solution may be separated from copper by a proper regulation of the voltage, which must be at least 2.05 for antimony. Truchot (Ann. chim. anal. appl. 10, 254) observed that heating molybdic acid on porcelain with concentrated sulphuric acid almost to the disappearance of fumes of the latter, cooling and breathing repeatedly on the dish causes a magnificent blue color. With vanadium present the color is green because of the mixture of yellow and blute.

Platinum Group and Gold.-Alvarez (Chem. News, 9I, I72; Gaz. chim. ital. 35, II, 42 I; Compt. rend. 140, I254) gave a new iodine compound of osmium which can be used as a test for the latter. To $2 \mathrm{cc}$. of aqueous I per cent. potassium iodide solution $20 \mathrm{cc}$. of pure concentrated hydrochloric acid $\left(22^{\circ}\right.$ Bé.) or better of phosphoric acid (sp. gr. I.7) are added, then a drop of the osmic acid solution. The green color may be shaken out with ether. $\mathrm{OsO}_{4}+\mathrm{IOHI}=$ $\mathrm{OsI}_{2} \cdot 2 \mathrm{HI}+{ }_{4} \mathrm{H}_{2} \mathrm{O}+3 \mathrm{I}_{2}$. The compound is soluble in water and ether, but insoluble in benzoic acid and chloroform. As a test for rhodium the same author ( $L O c$. cit. 9I, 216;35, II, 43I ; 140, I34I) recommended the blue liquid formed when the green $\mathrm{Rh}(\mathrm{OH})_{4}$ is oxidized in alkaline solution by chlorine or hypochlorite. A rhodium salt solution treated with an excess of sodium hydroxide and chlorine passed in turns reddish yellow, intense red, then becomes cloudy, a fine green precipitate comes out and this finally dissolves, forming a blue solution like ammoniacal copper; the color is that of Claus's sodium perrhodate, $\mathrm{Na}_{2} \mathrm{RhO}_{4}$. Nordenskjöld (Svensk Kemisk Tidskrift, I905, 54; through Pharm. Ztg. 50,633 ) gave a technical determination of the platinum metals. Iridium and rhodium do not dissolve in aqua regia and osmium is oxidized by concentrated aqua regia to osmic acid which can be separated by its volatility. Palladium, soluble in other acids, is separated first. The dilute platinum solution is precipitated with metallic magnesium, warmed for a quarter of an hour on the waterbath, filtered, washed, ignited gently, washed again after moistening with hydrochloric acid, ignited in a current of hydrogen, allowed to cool in carbon dioxide and weighed. The precipitate is treated again with dilute aqua regia, the platinum precipitated again with magnesium, washed well, finally acidified with hydrochloric acid, ignited and weighed. Quennessen (Chem. News, 92, 29; Bull. soc. chim. [3], 33, 875) separated platinum and iridium by means of precipitation with magnesium and extracting platinum from the ignited residue with dilute aqua regia. 
Separations.-Jannasch ( $J$, pr. Chem. $[2], 72,35)$, with Cohen (Loc. cit. p. I4), with Rühl (Loc, cit. p. I), with Schilling (Loc. cit. p. 26), and with von Maver (Ber. 38, 2 I 29, 2 I 30) gave a number of hydrazine and hydroxylamine separations as aluminum, ch romiun. and iron from copper and zinc, from manganese, magnesium and nickel, of iron and thorium from uranium, and of gold and platinum from other metals. Friedheim ( $Z$. anal. Chem. 44, 388), with Jacobius (Loc. cit. p. 465) and with Hasenclever (Loc. cit. p. 593), attacked the hydrogen peroxide, hydrochloric acid and hydroxylamine separations given in Jannasch's "Praktische Leitfaden der Gewich tsanalyse," saying that many of them would not work and that others were no better than the older methods. Lastly, Donath (Loc. cit. p. 698) claimed priority over both Jannasch and Friedheim in the gravimetric determination of manganese by hydrogen peroxide.

\section{ANALYSIS OF ORGANIC COMPOUNDS.}

Reagents and Quantitative Determinations.-Aloy and Laprade (Bull. soc. chim. [3], 33, 860) observed that a neutral solution of uranyl nitrate is colored a fine red by phenols. Ten grams of the nitrate were dissolved in $60 \mathrm{cc}$. of water and dilute ammonia added to beginning cloudiness, then the solution was filtered and the filtrate diluted to $100 \mathrm{cc}$. The solution to be tested was neutralized and $2 \mathrm{cc}$. of it treated drop-wise with the reagent till the maximum color was obtained. Mineral acids and alkalies cause the color to disappear. The reaction is in general sharp at dilutions of $I$ : I000 and visible at $I: 10,000$. Alverez (Chem. News, 9I, I25; Bull. soc. chim. [3], 33, 713; Gaz. chim. ital. 35, II, 432) used sodium peroxide as a test for the polyphenols, their isomers and higher organic compounds. He mixed 0.2 gram of the peroxide, $0.04-0.05$ gram of the polyphenol and $5 \mathrm{cc}$. of absolute alcohol, then after $4^{-6}$ minutes added $\mathrm{I} 5 \mathrm{cc}$. of water. He obtained:

substance.

Pyrocatechol.

Resorcino1.

Hydroquinone.

Pyrogallol.

Oxyhydroquinone. $[\mathrm{r}, 2,4]$

Phloroglucinol.

Orcinol.

Methylpyrocatechol.

Thymohydroquinone.
Color in alcohol.

Flesh, then green and Reddish brown. brown.

Yellow, then greenish. Darker green.

Reddish yellow.

Reddish brown.

Red-violet shades.

Red-violet.

Flesh-colored.

Blue-violet, then red.

Intense red.
Orange.

Red with yellow borders, after 24 hours orange.

Yellow.

Deeper violet, finally almost colorless.

Rose-red.

Reddish brown with yellow edges.

Wine-red, finally colorless.

Guérin (J. pharm. chim. [6], 21, I4) gave a list of the color reactions obtained with alcohols (except methyl and ethyl) and with 
substances containing the hydroxyl group when treated with $5^{-6}$ drops of a saturated aqueous solution of furfurol in the presence of concentrated sulphuric acid. Solid compounds were dissolved in concentrated sulphuric acid. The color was usually some shade of violet. Weehuizen (Pharm. Weekblad, 42, 27I) recommended phenolphthalin as a reagent for detecting hydrocyanic acid. Phenolphthalin solution made alkaline with sodium hydroxide and some I:2000 copper sulphate added, then treated with the hydrocyanic acid solution yields in the cold a red color, the phenolphthalin being oxidized to phenolphthalein. The color is distinctly visible with I part of acid in 500,000 of water. Lévy and Pécoul (Compt.rend. 140,98) modified Gautier's method for the detection of carbon monoxide by reduction of iodic acid at a temperature of $60^{\circ}-80^{\circ}$. They took up the iodine directly in 3-4 cc. of chloroform protected from the air by a layer of distilled water and then compared the color of the solutions with that of type solutions. With a special apparatus they detected I part carbon monoxide in 20,00o in a mass of 4 liters of air, or an amount of illuminating gas no longer detectable by its odor. Stortenbeker (Rec. trav. chim. 24, 66) detected iodoform in meat samples by distillation with steam. The fatty acids passing over with the iodoform were neutralized and the latter extracted with ether. The ether residue recrystallized from acetic acid gave well developed hexagonal crystals easily recognizable under the microscope. Sudborough and Thomas (Pr. Chem. Soc. 21, 88; J. Chem. Soc. 87, 1752) determined acetyl groups by distilling with steam the acetyl derivative (0.5-I.o gram) added to a Io per cent. solution of pure benzenesulphonic acid until the distillate ceased to be acid. The distillate was then titrated with barium hydroxide, using phenophthalein as indicator. Naphthalene $\alpha$-or $\beta$-sulphonic acid could be used instead of benzenesulphonic acid.

Alcohols and Aldehydes.-Kahn (Pharm. Ztg. 50, 651) tested for methyl alcohol in liquids containing ethyl alcohol by diluting 0.5 -I.O cc. of the liquid with Io volumes of water in a test-tube, putting repeatedly into the liquid a glowing copper spiral, adding $5 \mathrm{cc}$. of milk and a few drops of ferric chloride and allowing this liquid to flow carefully upon a few cc. of concentrated sulphuric acid without mixing. In the presence of methyl alcohol a violet zone at the contact surface between the two liquids was obtained inside of three minutes. Utz (Pharm. Centrh. 46, 736) gave a test very like this one. Lindet (Bull. assoc. chim. sucr. dist. 22, 475) recommended a modification of Eury's test for a rapid detection of formaldehyde in alcohol denaturized with it. He broke up a piece of dry casein in Io cc. of the alcohol, added a few drops of ferric chloride solution, then ro $\mathrm{cc}$. of phosphoric acid and $10-15 \mathrm{cc}$. of sulphuric acid and obtained a violet then a brown color. The delicacy is $\mathrm{I}$ : 
300,000. Schuch (Z. landw. Vers. Wes. Ost. 8, 1058) criticized Lindet's test, saying that dilute acetaldehyde, pure water and alcohol will give the reaction. He modified Arnold and Mentzl's test, distilling to $\mathrm{cc}$. from $300 \mathrm{cc}$. of wine with good cooling, then shaking $5 \mathrm{cc}$. of the distillate with $1.5 \mathrm{cc}$. of a solution of phenylhydrazine hydrochloride (I:50), adding four drops of ferric chloridé and $10-12$ of concentrated sulphuric acid. The color is red and the reaction is delicate to $I: 200,000$. Schulze (Loc. cit. p. I 55 and Chem. Ztg. 29, 976) and Henkel and Roth ( $Z$. angew.Chem. I8, 1936) made comparative studies of the various methods for the determination of glycerol. Braun (Chem.Ztg. 29, 763) and Strauss (Loc. cit.p. IO99) gave modifications of the bichromate method. Shukoff and Schestakoff (Z. angew. Chem. I8, 294) determined glycerol directly by mixing the sample with sodium sulphate dehydrated by ignition and then extracting in a Soxhlet apparatus with dry acetone. The acetone might be subsequently distilled off and the glycerol weighed directly in a closed vessel. The mixture should be made slightly alkaline before extraction with potash. The acetone extraction should last 4 hours and the glycerol should be dried for $4-5$ hours at $75^{\circ}-80^{\circ}$ in an air-bath to constant weight. The Dynamitfabrik Schlebusch (Loc. cit. p. 1656) reviewed the above method and recommended a filtration before making the liquid alkaline, also drying for $5^{-6}$ hours at $90^{\circ}-95^{\circ}$. The method gives slightly too high results. Landsberger (Chem. Rev. Fett.- Harz.- Ind. I2, I 50 ) compared the above method with the acetin method of Lewkowitsch and found the results of the two methods to agree generally very well. Nierenstein (Collegium, 1905 , p. 158 ) observed that formaldehyde gives a brown-red color with 0.5 per cent. phloroglucinol solution. Seyewitz and Bardin (Bull. soc. chim. [3], 33, Iooo) determined acetaldehyde by diluting the solution to be determined to a content of 7-8 per cent., then putting ro cc. of this solution into $40 \mathrm{cc}$. of exactly neutralized Io per cent. sodium sulphite solution and titrating with standard sulphuric acid in the presence of a drop of 2 per cent. alcoholic phenolphthalein. The mixture should be cooled to $4^{-} 5^{\circ} \cdot{ }_{2} \mathrm{Na}_{2} \mathrm{SO}_{3}+$ ${ }_{2} \mathrm{CH}_{3} . \mathrm{CHO}-\mathrm{H}_{2} \mathrm{SO}_{4}=\left(\mathrm{NaHSO}_{3}+\mathrm{CH}_{3} . \mathrm{CHO}\right)_{2}+\mathrm{Na}_{2} \mathrm{SO}_{1}$. Voisenet (Loc. cit. p. II98) gave a very delicate test for formaldehyde and for albumens. He poured $2-3 \mathrm{cc}$. of water over about 0.1 gram of finely powdered egg albumen or put $2-3 \mathrm{cc}$. of an albumen solution in a test-tube, added a drop of 5 per cent. solution of formaldehyde and diluted with 3 volumes of a strong nitrots acid solution $(0.5 \mathrm{cc}$. $\mathrm{HCl}$ of density $1 . \mathrm{I} 8$ added to I liter of a 3.6 per cent. solution of $\mathrm{KNO}_{2}$ ). On mixing, a reddish color appeared and after 5 minutes an intense violet-blue. Heating to $50^{\circ}$ favored the coloration. No color is obtained without the aldehyde except a weak red one after hours. By use of a weak nitrous 
acid solution ( $0.25 \mathrm{cc}$. of acid added to the nitrite instead of 0.5 cc.) and by warming to $50^{\circ}$ for 20 minutes I part aldehyde in I0,000,000 can be detected. The test is more delicate if carried out immediately after addition of the aldehyde but even after 48 hours I part in $I, 000,000$ can be detected. The test may be used for the detection of formaldehyde in foods, etc.

Ketones and Acids.-Kutscherow (Z.anal. Chem. 44, 622) stated that 0.3 gram of vanillin in $5 \mathrm{cc}$. of pure alcohol gives with I cc. of sulphuric acid no color or a pale yellow one, depending on the purity of the spirits. If these contain I per cent. of ketones intense fine colors are obtained, carmine-red with acetone and blue with the higher ones, sometimes with a shade of green which disappears shortly. The acetone color changes to citron-yellow on dilution with water, the blue of the others decreasing in intensity only as colors do on dilution with an indifferent solvent. The diluted acetone color becomes intense orange-red if the solution be made alkaline with caustic potash or soda, while the other ketone solutions become decolorized or pale yellow. The colors can be used for an approximate determination of the amount of ketones present. Amyl alcohol and furfurol do not interfere but aldehydes do. Bodländer $(Z$. Elektrochem. II, 185) gave an electrometric determination of carbon dioxide. Water takes up carbon dioxide in proportion to its partial pressure, and a corresponding amount of hydrogen ions are released. The latter is a measure of the carbon dioxide and may be easily determined. For practical purposes the combination $\mathrm{Ag}|\mathrm{AgCl}| \mathrm{KCl}+$ $\mathrm{KHCO}_{3}+\mathrm{K}_{2} \mathrm{SO}_{4} \mid \mathrm{PtO}_{2}$ is a good one. The same solution surrounds both electrodes. By use of air containing 0.03 per cent. carbon dioxide, the electromotive force is 0.268 volt. Sulphur dioxide must be removed. Methane in mine gases can thus be determined, converting it into carbon dioxide by burning over hot copper oxide. Croner and Cronheim (Berl. klin. Wochschr. 42, Io80) gave a new test for lactic acid, using the Vournasos principle. A few cc. of the juice suspected to contain lactic acid were diluted with water, made strongly alkaline with ro per cent. potassium hydroxide, boiled for a few minutes, then treated with an iodine solution (2 grams $\mathrm{KI}$ in at most $5 \mathrm{cc} . \mathrm{H}_{2} \mathrm{O}$, I gram sublimed $\mathrm{I}$, the solution filtered through glass wool and diluted to $50 \mathrm{cc}$., then $5 \mathrm{cc}$. of aniline added, the whole kept in a dark colored bottle). In the presence of lactic acid the unpleasant odor of phenyl isocyanide is obtained. The reaction is delicate to 0.0025 gram of acid in roo cc. of juice. Rupp (Arch. Pharm. 243, 69) determined formic acid titrimetrically by diluting, in a glassstoppered flask, a suitable volume of bromine.lye (I 5 grams $\mathrm{NaOH}$, I 5 grams $\mathrm{Br}$ and $\mathrm{H}_{2} \mathrm{O}$ to $500 \mathrm{cc}$.) of known iodine value to about 70-IOO cc. with water, then adding a known amount of the formic acid solution (not more than enough to use up about half of the 
bromine). Then he added dilute hydrochloric acid from a burette till the bromine color began to remain, allowed the whole to stand for 30 minutes in the dark, added I gram of iodine and $10-20 \mathrm{cc}$. of hydrochloric acid and titrated with tenth-normal thiosulphate. One cc. thiosulphate $=0.0023$ gram of formic acid.

Cyanogen Compounds.-Astruc and Pegurier (Ann. chim. anal. appl. 10, 302) used Lemaire's principle of precipitation with picric acid for the removal of antipyrine in the determination of pyramidone. They dissolved $0.23 \mathrm{I}$ gram of pyramidone in ro cc. of water, precipitated by means of $40 \mathrm{cc}$. of twentieth-normal picric acid, shook for a few minutes and titrated back $25 \mathrm{cc}$. of the filtrate with twentieth-normal alkali and phenolphthalein. The pryamidone content $=(40-4 n)+5$ if $n=$ the number of cc. of alkali. Pegurier (Loc. cit. p. 392) found also that antipyrine behaves toward helianthine as a neutral substance while pyramidone acts like a monobasic one. He therefore recommended the solution of $0.231 \mathrm{gram}$ of the sample in ro cc. of water, neutralizing exactly with tenth-normal acid and then carrying out the titration with picric acid. Bourcet (Bull. soc. chim. [3], 33, 572 ) gave a test for antipyrine in the presence of pyramidone. He dissolved $\mathrm{I}_{-2}$ grams of the sample in $4-5 \mathrm{cc}$. of cold water, added then 2 drops of concentrated sulphuric acid and 2 drops of a saturated sodium nitrite solution and shook the mixture. Pure pyramidone gives first a blue-violet color, becoming later colorless, especially with excess of nitrite. With antipyrine present a blue-violet color is also first obtained which becomes, with more nitrite, a stable green-blue. One per cent. of antipyrine can be detected with certainty. Patein ( $/$. pharm. chim. [6], 22, 5; Bull. soc. chim. [3], 33, 845) gave a test likewise for these two substances, depending on the fact that antipyrine forms with formaldehyde in the presence of hydrochloric acid diantipyrinemethane while pyramidone remains unchanged. One gram of the pyramidone in $5 \mathrm{cc}$. of water is treated with $5 \mathrm{cc}$. of water, then $2 \mathrm{cc}$ of 40 per cent. formaldehyde and allowed to stand 4 days at ordinary temperatures or heated for 4 hours on the water-bath, diluted with io $\mathrm{cc}$. of water and made alkaline with ammonia. Without antipyrine the liquid remains clear, but with it insoluble diantipyrinemethane is obtained. Guérin (J.pharm. chim. [6], 22, 433) modified the methods of Liebig and of Fordos and Gélis for the rolumetric determination of free hydrocyanic acid in aqueous solutions, adding borax to the acid solution before titration with silver nitrate or with iodine. Io cc. of dilute acid solution are treated with Io cc. of 3 per cent. borax solution and titrated with 3.148 per cent. silver nitrate or with 9.407 per cent. iodine solution to the appearance of a permanent cloud or to a yellow color. i ce. $\mathrm{AgNO}_{3}=$ I cc. $\mathrm{I}=0.00 \mathrm{I}$ gram HCN. $2 \mathrm{HCN}+\mathrm{Na}_{2} \mathrm{~B}_{4} \mathrm{O}_{7}=\mathrm{H}_{2} \mathrm{~B}_{4} \mathrm{O}_{7}+2 \mathrm{NaCN}$. 
$2 \mathrm{NACN}+\mathrm{AgNO}_{3}=(\mathrm{AgCN} \cdot \mathrm{NaCN})+\mathrm{NaNO}_{3} . \quad \mathrm{AgCN} \cdot \mathrm{NaCN}+$ $\mathrm{AgNO}_{3}=2 \mathrm{AgCN}+\mathrm{NaNO}_{3} . \quad 2 \mathrm{HCN}+2 \mathrm{I}_{2}=2 \mathrm{ICN}+2 \mathrm{HI}$. ${ }_{2} \mathrm{HI}+\mathrm{Na}_{2} \mathrm{~B}_{4} \mathrm{O}_{7}=\mathrm{H}_{2} \mathrm{~B}_{4} \mathrm{O}_{7}+\mathrm{NaI}$. Von Mahler (Chem. Ztg. 29, 32) gave a qualitative test for saccharin. He evaporated the ether solution of the substance to be tested, put the dry residue into a little tube sealed at one.end and containing already a piece of sodium or potassium, warmed and threw the yet hot tube into a beaker of freshly prepared sodium nitroprusside solution. The resulting test for sulphur compounds is proof of saccharin under these conditions. Procter (Pr. Chem. Soc. 21, 62; J. Chem. Soc. 87, 242) gave a quantitative determination of saccharin. One-half to $\mathrm{I}$ gram of the powdered substance was put into a $200 \mathrm{cc}$. glass-stoppered flask with $50-75 \mathrm{cc}$. of freshly boiled distilled water, $I-2$ crystals of potassium iodide added, then ro cc. of 5 per cent. potassium iodate solution and the whole shaken. The orthobenzoic acid sulphinide dissolves immediately, liberating an equivalent amount of iodine which is titrated with tenthnormal thiosulphate. The parasulphaminobenzoic acid dissolves more slowly. I cc. tenth-normal thiosulphate $=0.0183$ gram saccharin. To determine both constituents he made the total titration and also determined the ammonia formed by boiling the sample with Ioo-fold the quantity of normal hydrochloric acid. The number of cc. of tenth-normal acid corresponding to this ammonia subtracted from the number of $\mathrm{cc}$. of tenth-normal thiosulphate of the total titration and the difference multiplied by 0.0201 gives the amount in grams of the para compound. Leuba (Ann. chim. anal. appl. I0, 2I8) determined copper ferrocyanide by boiling with 5 per cent. oxalic acid for two hours with a return-flow condenser, filtering and washing the green-yellow precipitate, dissolving it in nitric acid and adding this solution to the filtrate, in which copper and iron were determined as usual. $\mathrm{Cu}_{2} \mathrm{Fe}(\mathrm{CN})_{6}+{ }_{3} \mathrm{H}_{2} \mathrm{C}_{2} \mathrm{O}_{4}={ }_{2} \mathrm{CuC}_{2} \mathrm{O}_{4}+\mathrm{FeC}_{2} \mathrm{O}_{4}+6 \mathrm{HCN}$. Rupp (Arch. pharm. 243, 458) gave a method for the titrimetric determination of cyanides, sulphocyanates and chlorides. Cyanides are oxidized in alkaline solution by iodine to cyanates. $2 \mathrm{NaOH}+\mathrm{I}_{2}=\mathrm{NaIO}+\mathrm{NaI}+\mathrm{H}_{2} \mathrm{O} . \mathrm{NaIO}+\mathrm{CN}^{\prime}=\mathrm{NaI}+$ $\mathrm{CNO}^{\prime}$. Io cc. of about 4 per cent. potassium cyanide solution were mixed with 5-20 cc. of normal potassium hydroxide in a flask and $25 \mathrm{cc}$. of tenth-normal iodine solution added with shaking, the whole diluted after standing to Ioo cc., acidified with dilute hydrochloric acid and the precipitated iodine titrated with tenth-normal thiosulphate. Sulphocyanates may be titrated in the same manner. I cc. thiosulphate $=3.25 \mathrm{mg}$. $\mathrm{KCN}$ $=\mathrm{I} .2 \mathrm{I} 25 \mathrm{mg}$. KCNS. Cyanides in bicarbonate alkaline solution behave thus: $\mathrm{CN}^{\prime}+\mathrm{I}_{2}=\mathrm{ICN}+\mathrm{I}^{\prime}$. On acidification, the reaction may be expressed thus: $\mathrm{ICN}+\mathrm{HI}=\mathrm{HCN}+\mathrm{I}_{2}$. No iodine is therefore used. Sulphocyanates under the same condi- 
tions give $\mathrm{CNS}^{\prime}+8 \mathrm{I}==\mathrm{CNI}+\mathrm{SO}_{3}+7 \mathrm{I}$, and on acidification $\mathrm{ICN}+\mathrm{HI}=\mathrm{HCN}+\mathrm{I}_{2}$. Hence 6 atoms of iodine are used. Therefore, in a mixture of cyanide and sulphocyanate the latter is easily determined. With chlorides also present all three are determined as silver salts, then in one portion cyanide and sulphocyanate are titrated and finally sulphocyanate alone in another.

Carbohydrates.-Ewers ( $Z$. offentl. Chem. I I, 374) concluded that direct polarization should not be used as a basis for the detection of starch sugar in fruit juices because of its great variations and that in its place total sugar should be determined. He would test the fruit juice for invert sugar. If over 2 per cent. is found he would determine the total sugar gravimetrically. The presence of starch sugar may be accepted when for too per cent. sugar calculated as cane-sugar the levorotation of the invert solution of 26 grams of syrup in roo $\mathrm{cc}$. of water in a $200 \mathrm{~mm}$. tube polarizes $28^{\circ}$ or less. De Graaf (Pharm. Weekblad, 42, 685) found that free diphenylhydrazine boiled with lactose and $2-3$ drops of acetic acid gave a yellow-red, then brown-ted, dark black-green and finally brown liquid. If 70 per cent. alcohol was added after the green color appeared a characteristic green liquid was obtained. The green color was soluble also in amyl alcohol, chloroform and ether but not in water or carbon bisulphide. Glucose and saccharose gave only the brown-red color. Höglund (Z. Ver. Rübenzuck.- Ind. I905, p. I048) found that cellulose (of filter-paper or of the beet itself) caused a loss of sugar by absorption in the polarization of alcoholic sugar solutions. Kopecky (Colleginm, i 905 , p. I 50 ) detected cellulose in hide powder by moistening $0.2-0.3 \mathrm{gram}$ of the latter with a solution of iodine and zine chloride $(6$ grams KI-1- IoO grams $\mathrm{ZnCl}_{2}$ of density $\mathrm{I} .80$ saturated with $\mathrm{I}$ ) and after $2-3 \mathrm{~min}$ tues adding $25 \mathrm{cc}$. of water and shaking. On a white background the deep violet cellulose is to be distinguished easily from the yellow hide substance. Lavalle (Ber. 38, 21 \%o; Chem. News, 91, 299) modified the Fehling method of determining sugar by heating 5 or to cc. of Fehling solution with $30 \mathrm{cc}$. of sodium hydroxide $(\mathrm{I}: 3)$ and 50 or $60 \mathrm{cc}$. of water to beginning boiling in a $200 \mathrm{cc}$. dish and then gradually adding the sugar. The operation is ended with the disappearance of the blue color; the cuprous oxide does not precipitate. This method was recommended by Sidersky (Bull. assoc. chim. sucr. dist. 23, 426). Ling and Rendle (Analyst, 30, 182) determined the end point of the cuprous oxide precipitation by the use of ferrous sulphocyanate. They dissolved $\mathrm{x}$ gram of ferrous ammonium sulphate and I gram of ammonium sulphocyanate in ro $\mathrm{cc}$. of water at $45^{\circ}-50^{\circ}$, cooled and added $50 \mathrm{cc}$. of concentrated hydrochloric acid. The brownish red color was removed with a little zinc dust and a later red in the same way. The reagent became 
instantly red on the addition of copper sulphate and $2 \mathrm{cc}$. of Fehling solution in a liter could be detected with it. Wolff (Ann. chim anal. appl. ro, 427) observed that the cuprous oxide obtained in the ordinary way may be treated with ferric sulphate in sulphuric acid solution and the ferrous sulphate formed titrated with permanganate. Another modification of the Fehling method for small amounts of sugar was given by Bilinski (Pharm. Post, 38, 85, 98; Monatsh. 26, 133). Fifty cc. of urine were treated with uranyl nitrate $(4: 100)$ till a drop of the mixture colored powdered potassium ferrocyanide brown-red. The urine was added to a definite quantity of the Fehling solution so as to have all the copper reduced. When it was reduced the slightest excess of sugar would reduce also the uranium, giving the precipitated cuprous oxide a green or brownish color. Lührig (Pharm. centrh. 46, 95I) found that there was considerable error in the use of animal charcoal in the methods for the determination of starch syrup, because of its absorptive power. It causes an error of as much as Io per cent. of starch sugar in the official methods. The method of Juckenack for the investigation of fruit juices contains this error. Rank ( $Z$. Osterr. A poth.-Ver. 43, ro38) determined sugar in urine by decomposing $2-3 \mathrm{cc}$. of the latter with the same volume of potassium hydroxide solution, adding $0.1-0.2$ gram of phenylhydrazine and boiling until solution was effected. On slow acidification with dilute acetic acid the solution became cloudy if sugar was present. The test was even more certain if the urine were clarified with lead acetate and the test carried out on the filtrate. One-tenth per cent. of sugar or less could be detected.

Alkaloids-Alverez (Chem. News, 91, I 79;Compt.rend. I40, I540; Gaz. chim. ital. 35, II, 429) gave a new reagent for aconitine. The alkaloid (0.0005-0.0002 gram) was treated with 5-10 drops of bromine, warmed somewhat in a salt-water bath, then $\mathrm{I}-2 \mathrm{cc}$. of fuming nitric acid added and evaporated in the same bath with the addition of some more bromine, when the acids lose their color and a yellow oxidation product is formed. Then $0.5^{-1.0} \mathrm{cc}$. of a saturated solution of caustic potash in alcohol (made from pure alcohol of density 0.796 ) was added, evaporated to dryness, giving a red-brown mass, allowed to cool and 5-6 drops of a 1o per cent. aqueous copper sulphate solution added, giving a deep green color. Reichard's (Pharm. Centrh. 46, 252, 309, 385, 479, 644, 846, 935 and Pharm. Ztg. 50, 314, 430, 877) series of articles on the reactions of nicotine, coniine, quinine, cinchonine, aconitine, sparteine, veratrine, caffeine, theobromine, quinidine, cinchonidine and piperine is worthy of note again as last year.

Coloring Materials and Oils.-Knecht ( $J$. Soc. Dyers Colorists, 21 ; Chem. Centr. I905, I, p. 777) determined methylene blue by reduction with titanium trichloride. One gram of the 
blue was dissolved in $250 \mathrm{cc}$. of water, $50 \mathrm{cc}$. of the solution put into a conical flask and warmed after the addition of a little hydrochloric acid. Carbon dioxide was then passed into the flask and its contents were titrated with titanium trichloride solution to decolorization. A similar method he applied to other coloring-materials reducible by the trichloride. Majstorovic( Chem. Ztg. 29, 309) found that in the mean a rise of temperature of $0.5^{\circ}$ in the flashing point of petroleum indicated a vapor loss of $0.1 \mathrm{I} 3$ per cent. from a closed reservoir of $1,000,000 \mathrm{~kg}$. content. He thinks it possible to determine the amount of loss by evaporation in this way. Budde (Veröffentl. aus dem Gebiete des MilitärSanitätswesens, 1905, No 29; Phamn. Ztg. 50, 432; A poth. Ztg. 20, 42I) determined pure rubber in rubber goods by pouring over I gram of the sample in a Ioo cc. measuring flask carbon tetrachloride, allowing to stand till division of particles or solution had taken place, filling to the mark and filtering through glass wool Io cc. for analysis. This he diluted to $50 \mathrm{cc}$. with carbon tetrachloride, and added $50 \mathrm{cc}$. of a brominating liquid ( 16 grams $\mathrm{Br}+\mathrm{I}$ gram I dissolved in $\mathrm{CCl}_{4}$ to $\mathrm{I} 000 \mathrm{cc}$.), obtaining after a time a precipitate. As soon as the supernatant liquid was clear he added 50 cc. of absolute alcohol. The tetrabromide of rubber was brought on to a filter (dried previously at $50^{\circ}-60^{\circ}$ and weighed), washed first with a mixture of 2 parts carbon tetrachloride and I part alcohol, then with pure alcohol and dried at a temperature not exceeding $60^{\circ} .45^{6}$ grams of this compound correspond to I36 of pure rubber. Torrey (India Rubber J, 30, 41\%, 467) gave a new method for the determination of rubber based on the color reaction caused by treating the rubber with concentrated nitric acid and then rendering alkaline. The color is deep red. Ditmar (Gummiztg. 20, 204) said Torrey's method has no scientific foundation, that rubber breaks up in a complex way and that the one coloring-matter, $\mathrm{C}_{10} \mathrm{H}_{12} \mathrm{~N}_{2} \mathrm{O}_{6}$, is only a small part of the resulting products, oxalic acid and a second coloring body being among the others. Further, the ratio of these products is not constant.

Milk.-Bellier (Ann. chimanal. appl. тo, 268) gave a new method of milk analysis. Prismatic pieces of poor quality sponge of about 0.2 gram weight were pressed out with very dilute hydrochloric acid till no more sand appeared, then washed with alcohol, ether and finally water. One was dried at $80^{\circ}$ and weighed with a similarly dried filter, then $5 \mathrm{cc}$. of milk was completely soaked up into it. The sponge hung on a thread, was dried at $80^{\circ}$, put into the filter and weighed after cooling. The increase in weight multiplied by 20 gives the grams of extract in Ioo cc. of milk. The sponge was then extracted in a Soxhlet apparatus with water-free ether, the fat being removed by the fifth siphonation. The sponge was weighed after drying and cooling 
and the fat obtained by difference. The albumens were rendered insoluble by exposing the sponge to the vapor from a gently boiling formaldehyde solution. The sponge was then allowed to stand for a quarter of an hour in 50 per cent. alcohol containing 5 per cent. acetic acid, then it was hung in water, changing the water five times. In the sponge were left only the albumens and at most 0.0 I gram of mineral matter calculated to IOO cc. of milk. The difference between its weight at this point and the preceding weight multiplied by 20 gives the amount of milk-sugar and ash and 0.01 gram. The difference between the last weight and the original weight multiplied by 20 gives the amount of albumen in Ioo cc. of milk and o.or gram mineral matter, which may be taken as constant. The ash was determined directly in Io cc. of milk by ignition, and may be assumed for rapid work to be constant at 0.7 gram per roo cc. for unadulterated cow's milk. Bordasand Touplain (Compt.rend.140, 1099) gave also a new rapid method. Ten cc. of milk were allowed to drop into the tared tube of a centrifugal machine, in which there was 65 per cent. alcohol acidified with acetic acid, allowed to settle for a moment, whirled, decanted, stirred again with $30 \mathrm{cc}$. of 50 per cent. alcohol, decanted again and the lactose determined in the combined liquids by Fehling's solution. The milk residue was extracted twice, adding first each time $2 \mathrm{cc}$. of 96 per cent. alcohol, then $30 \mathrm{cc}$. of ether and whirling each time for a few minutes. The ethereal extract was evaporated in a tared vessel and the butter weighed after drying. The casein remains in the tube of the machine as a fine powder and is dried at a low temperature and weighed. The ash was determined in Io cc. of the milk by ignition.. Dekker (Pharm. Weekblad, 42, 977, IOO2) determined fat in milk by boiling ro cc. of the sample with Io cc. of concentrated hydrochloric acid in a flask until the casein had, to some extent, disappeared, shaking after cooling with $50 \mathrm{cc}$. of chloroform, adding after 5 minutes 3 grams of tragacanth and shaking again. Forty cc. of chloroform could be poured off the slime and this contained the fat of $8 \mathrm{cc}$. of milk. The chloroform was distilled off, the fat dried for an hour and weighed. Morres (Milch-Ztg. 34, 573, 585) recommended the alcohol test as of most value in determining the keeping quality of milk. He added $2 \mathrm{cc}$. of nillk to $2 \mathrm{cc}$. of alcohol (68 per cent. by volume). The size of the flakes is a measure of the readiness of the milk to curdle, sour milk yielding great flakes. With alcohol 4 degrees of acidity can be detected as against 5.5 by heating. Utz (Chem. Ztg. 29, 669) gave a new test for formalin in milk. Milk and hydrochloric acid (density I.I9) treated with a few grams of vanillin gives a violet-red color, but if formalin is present the liquid is colored yellow. Piperonal and paraoxybenzaldehyde give similar reactions but not so delicate.

Butter and Blood.-Soltsien (Pharm. Ztg. 50, 398 and Chem. 
Rev. Fett.- Harz-Ind. I2, 125) used acetone to determine fat, water and non-fat in butter and cream. Five grams of cream were put into a glass-stoppered, weighed Erlenmeyer flask containing a few pieces of pumice with Ioo cc. of a mixture of I volume of acetone and 1.5 volumes of absolute ether and shaken hard for half a minute. The flask was cooled, the stopper washed with the acetone mixture and the contents of the flask heated to beginning boiling with a return-flow condenser. After cooling, the liquid was poured through a weighed filter into a weighed distilling flask (about $300 \mathrm{cc}$. size) containing a few pieces of pumice. The residue in the Erlenmeyer flask was weighed, 3 times with $20 \mathrm{cc}$. each time of the acetone mixture, with a little warming, finally with absolute ether, pouring the washings through the filter. In the filtrate the fat was determined by evaporation of the solvent and weighing of the residue. The Erlenmeyer flask and the filter were dried to constant weight for the non-fat. One hundred per cent.-(per cent. fat + per cent. non-fat) $=$ per cent. water. With butter Io grams were used. Bence (Centr. Phrsiol. I9, I98) gave a new method for determining the volume of the blood corpuscles in small masses of blood. He added to roo parts of blood a known amount of 0.9 per cent. sodium chloride solution and gave the following equations: $\mathrm{S}(\mathrm{R}-\mathrm{1}-3328)+\mathrm{K}(\mathrm{I} .3342$ $-\mathrm{I} .3328)=\mathrm{S}+\mathrm{K}\left(\mathrm{R}_{x}-\mathrm{I} .3328\right)$ or $\mathrm{S}=\mathrm{K}\left(\mathrm{R}_{x}-\mathrm{I} .3342\right)$ $\left(\mathrm{R}-\mathrm{R}_{x}\right)$, where $\mathrm{S}=$ amount of serum, $\mathrm{R}=\mathrm{its}$ refractive index, $\mathrm{K}=$ amount of sodium chloride solution of refractive index 1.3342 if that of water is 1.3328 . The refractive index $\mathrm{R}_{x}$ of the mixture of $\mathrm{S}$ and $\mathrm{K}$ lies between $\mathrm{I} .3342$ and $\mathrm{R}$. With $\mathrm{R}$, $\mathrm{K}$ and $\mathrm{R}_{x}$ known, $\mathrm{S}$ can be calculated. Koeppe (Pfiuger's Arch. I70, I87) determined the volume of tile blood corpuscles by cerltrifuging the blood in graduated oil pipettes at 5000 or more revolutions per minute.

A portion of the work for this review was done in the library of the department of chemistry of Cornell University, through the courtesy of Professor L. M. Dennis, for which the writer desires to express his thanks.

LNIVERSITY OF NEBRASKA,

LINCOLN, NEBRASKA.

\section{NEW BOOKS.}

GeSAMMELTE WeRKE. .BY ADOLF VON BAEYER. Vol. I, 990 pp., with an introduction, I32 pp. Vol. II, II94 pp. Braunschweig: Vieweg und Sohn. 1905. Price, bound, 20 marks.

It is almost with a feeling of reverence that $I$ attempt to give the readers of the Journal a brief outline of the colossal work of one of the greatest chemists of the age, Adolf von Baeyer. I am at a loss even in summarizing these two great volumes, for an 